\title{
MONUMENTOS, ARQUEOLOGÍA Y PERSPECTIVA LOCAL. EL CASO DE LOS MONTÍCULOS BASUREROS DEL VALLE DE AMBATO (NOROESTE DE ARGENTINA)
}

\author{
MONUMENTS, ARCHAEOLOGY AND LOCAL VIEW. THE CASE OF THE \\ WASTE MOUNDS OF AMBATO VALLEY (NORTHWEST OF ARGENTINA)
}

Marcos R. Gastaldi ${ }^{1}$

\begin{abstract}
Resumen
En el valle de Ambato (Catamarca, Argentina) uno de los rasgos arqueológicos más visibles son las estructuras monticulares de tierra, algunas transformadas en plataformas de piedra, de hasta $3 \mathrm{~m}$ de alto. Dichas estructuras no se construyeron de una vez, sino que son producto de la acumulación progresiva y por largo tiempo de los desechos provenientes de la limpieza de los pisos de las casas a las cuales estaban asociadas. Los pobladores locales las usan como demarcadores toponímicos;

"Bordo", "Altillo" e "Iglesia" son algunos de los nombres propios que reciben. En este trabajo, retomando la apreciación de Mary Douglas de que la eliminación de la suciedad se trata de un esfuerzo positivo, más que negativo, por organizar el entorno, analizamos las implicancias que tuvo en la estructuración del espacio doméstico y en la definición de los grupos sociales que los habitaron, las prácticas de limpieza de los pisos de las habitaciones y la deposición de los desechos en dichas estructuras monumentales. Además, pondremos en tensión la interpretación arqueológica propuesta, con la perspectiva local sobre estos rasgos. Al final se discutirán las posibilidades de articulación de ambas miradas, y el rol de la arqueología en contextos de creciente presión por parte de actores externos, sobre tierras de comunidades
\end{abstract}

campesinas.

Palabras claves: Estructuras monticulares - sedimento memoria - mirada local - Andes.

\begin{abstract}
In the Ambato Valley (Catamarca, Argentina) one of the most visible archaeological features are the mound earth structures, some of them was transformed into stone platforms, up to 3 meters high. Those structures were not built at once, but they are products of the long-term progressive accumulation of waste from the cleaning of houses' floors to which they were associated. Local people use them as place names: "Bordo", "Altillo" and "Iglesia" (church) are some of the proper names they receive. In this paper, taking into account the appreciation of Mary Douglas that the removal of dirt is a positive effort rather than negative, for organizing the environment, we analyze the implications of cleaning practices of the rooms' floors, and its deposition in these monumental structures in the structure of domestic space and the definition of social groups that inhabited them. In addition, we will stress this interpretation arising from our archaeological practice with the local perspective on these features. At the end, we articulate an argument that questions the possibilities and connections of both views, and the role of archaeology in the context of increasing pressure by external actors, on lands of peasant communities.
\end{abstract}

Keywords: Mound structures - sediment - memory - local view - Andes. Recibido: agosto 2015. Aceptado: octubre 2016.
Mary Douglas (1973: 14) señalaba en su ya clásico ensayo Pureza y Peligro, que la suciedad, tal como la conocemos, consiste esencialmente en desorden: "[N]o hay suciedad absoluta: existe solo en el ojo del espectador. Evitamos la suciedad, no por un temor pusilánime y menos aún por espanto o temor religioso. Tampoco nuestras ideas de la enfermedad dan cuenta del alcance de nuestro comportamiento al limpiar o evitar la suciedad. La suciedad ofende al orden". En este sentido, aquélla es materia fuera de lugar, decía. Así, su eliminación no es un esfuerzo negativo sino un esfuerzo positivo por organizar el entorno.

En el valle de Ambato, ubicado en la Provincia de Catamarca en Argentina, sector sureste de los Andes meridionales (Figura 1), lugar donde concentramos nuestras investigaciones, una práctica recurrente de los habitantes del primer milenio DC fue la continua limpieza de los pisos de las casas y la acumulación progresiva de la "basura" en espacios que terminan, al cabo de un tiempo, adquiriendo una forma monticular (Gastaldi 2010; Gordillo 2009; Haber et al. 1996-97). Las inclusiones que contienen los diferentes estratos que componen los montículos basureros son representativas de gran parte de las cosas usadas en los sitios adosados a ellos: restos de animales consumidos, ceniza y carbón provenientes de la limpieza de los fogones domésticos, partes de muro de adobe de las paredes de las viviendas, pigmentos, instrumentos líticos, fragmentos de vasijas, fragmentos de pipas de cerámica, entre otras cosas (Cruz 2005; Fabra 2008; Gastaldi 2010, 2012; Gordillo 2009; Haber et

1 Instituto de Antropología de Córdoba (IDACOR-CONICET) y Museo de Antropología de la FFyH, Universidad Nacional de Córdoba. Hipólito Yrigoyen 174, Córdoba, CP 5000, ARGENTINA. Email: mrgastaldi@gmail.com 


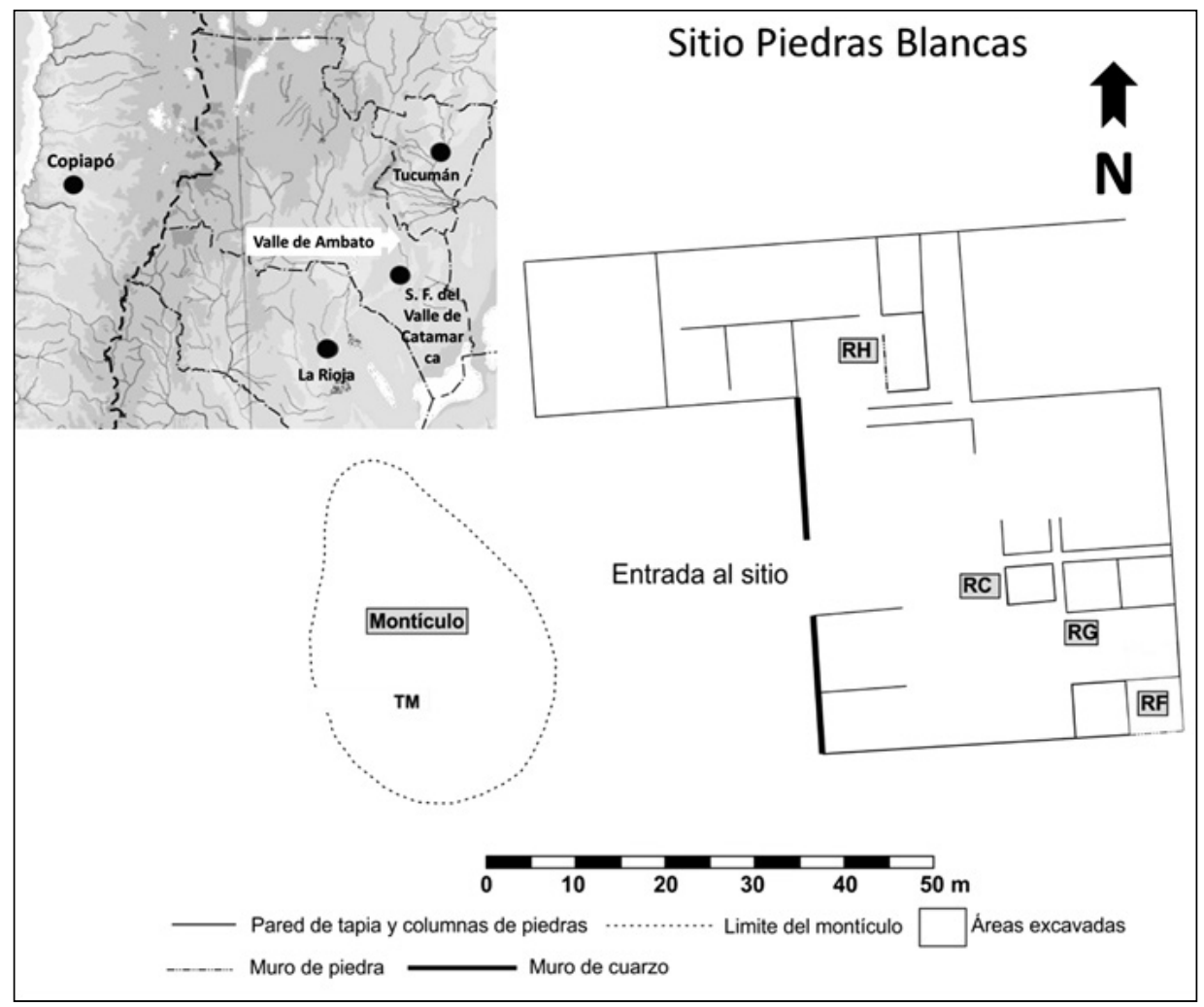

Figura 1. Plano general del sitio Piedras Blancas.

al. 1996-97). ${ }^{2}$ Se podría decir que las trayectorias biográficas de la mayoría de las cosas utilizadas en las viviendas terminan en estos lugares (Gastaldi 2010). Estos montículos, formados por esa sucesión de depósitos de desechos, llegan a alcanzar hasta $3 \mathrm{~m}$ de altura (Figura 2). Algunos de ellos fueron utilizados como "basurero" durante varios siglos (Cruz 2005; Fabra 2008; Gastaldi 2010; Gordillo 2009). En este trabajo, retomando los planteamientos de Douglas que hemos señalado, analizamos las implicancias que tuvieron las prácticas de limpieza de los pisos de las habitaciones y las depositaciones de estos restos en los montículos basureros, en la estructuración y reestructuración del espacio doméstico, y en la definición de los grupos sociales que los habitaron. Nos concentraremos en analizar esta dinámica en el sitio

2 Recientemente Bernarda Marconetto (com. pers. 2014) me señaló que algunos de los restos de combustión hallados en el montículo podrían corresponder a pequeños fogones realizados en la misma estructura. Esto se encuentra en investigación en estos momentos, por lo cual no se descarta que algunas de las acciones observadas en la estratigrafía correspondan a eventos hechos sobre la estructura. de vivienda de Piedras Blancas (Figura 1), dado que poseemos mayores volúmenes de excavaciones y contextos estratigráficos precisos, pero sin dejar de lado otros casos observados en el valle y zonas aledañas. Al final del texto actualizaremos el debate en relación a cómo estos lugares que se usaron durante varios siglos en el pasado, y se conformaron como estructuradores de las relaciones domésticas y comunitarias, aún hoy tienen significados propios para las personas que viven en el valle de Ambato. Este análisis nos permitirá adentrarnos en una discusión que ha cobrado mucha relevancia, en los últimos años, en el Noroeste de Argentina, extensible a varias regiones del país y de Sudamérica. Se ha vuelto una tarea ineludible para la arqueología, en contextos donde las comunidades campesinas locales reciben una constante presión sobre sus tierras, discutir las relaciones que se establecen entre discursos arqueológicos, cultura material y comunidades locales (Ayala 2007; Crespo 2006; Curtoni y Chaparro 2008; Endere 2011; Endere y Curtoni 2006; Gnecco y Ayala 2010; Jofré 2010; Jofré y Molina 2009; Haber 2011a; Quesada 2009). 


\section{* Casas y montículos en el valle de ambato}

El valle de Ambato está ubicado en el Departamento de Ambato de la Provincia de Catamarca, República Argentina (Figura 1). Forma parte de la provincia geológica de las Sierras Pampeanas Noroccidentales. Esta provincia geológica se caracteriza por poseer estrechos valles y bolsones, alternando con bloques o cordones elevados. En general los cordones montañosos poseen una dirección NNO-SSE. Uno de estos valles estrechos es el valle de Ambato, que constituye la porción septentrional del Valle de Catamarca. Posee una superficie de $1797 \mathrm{~km} 2$, bordeado al este por el macizo Balcozna-Lampazo de la sierra de La Graciana, que tiene una altura máxima de unos 1900 msnm, y al oeste por el macizo de Humaya (2278 m) de la sierra del Ambato-Manchado, cuya altura máxima es la del cerro Manchado, de $4351 \mathrm{msnm}$. En la llanura aluvial del fondo de valle, y en el mismo sentido de los cordones montañosos que la delimitan, corre el Río de Los Puestos o Nacimientos, que nace en los Altos de Singuil (1250 msnm).

Las investigaciones en este lugar se iniciaron en la década de 1970. En 1972 se realizaron las primeras prospecciones y excavaciones en el valle (Pérez Gollán y Heredia 1975). Desde el primer momento se identifica una larga historia de ocupación y desarrollo local, a partir del Período Formativo (Condorhuasi y Ciénaga) y lo que se denominó posteriormente como Período de Integración Regional vinculado al origen y desarrollo de la Cultura Aguada (Pérez Gollán y Heredia 1987; Pérez Gollán 1991). Este último período prehispánico ha sido caracterizado por la circulación de bienes con alto valor simbólico (alucinógenos, textiles y placas metálicas), que articularía redes de intercambio a gran escala regional entre diferentes grupos sociales que producirían la integración social y política de varias sociedades en el Noroeste de Argentina. En el caso del valle de Ambato, las investigaciones arqueológicas llevadas a cabo desde aquella época hasta la actualidad, permitieron observar a lo largo del primer milenio, y principalmente a partir del siglo $\mathrm{V}$ o VI DC, la formación de una sociedad con alto grado de heterogeneidad social en el valle (Assandri 2007; Fabra 2008; Laguens 2006; Marconetto 2008).

Los montículos basureros en la arqueología del valle de Ambato fueron identificados desde los inicios de las in-
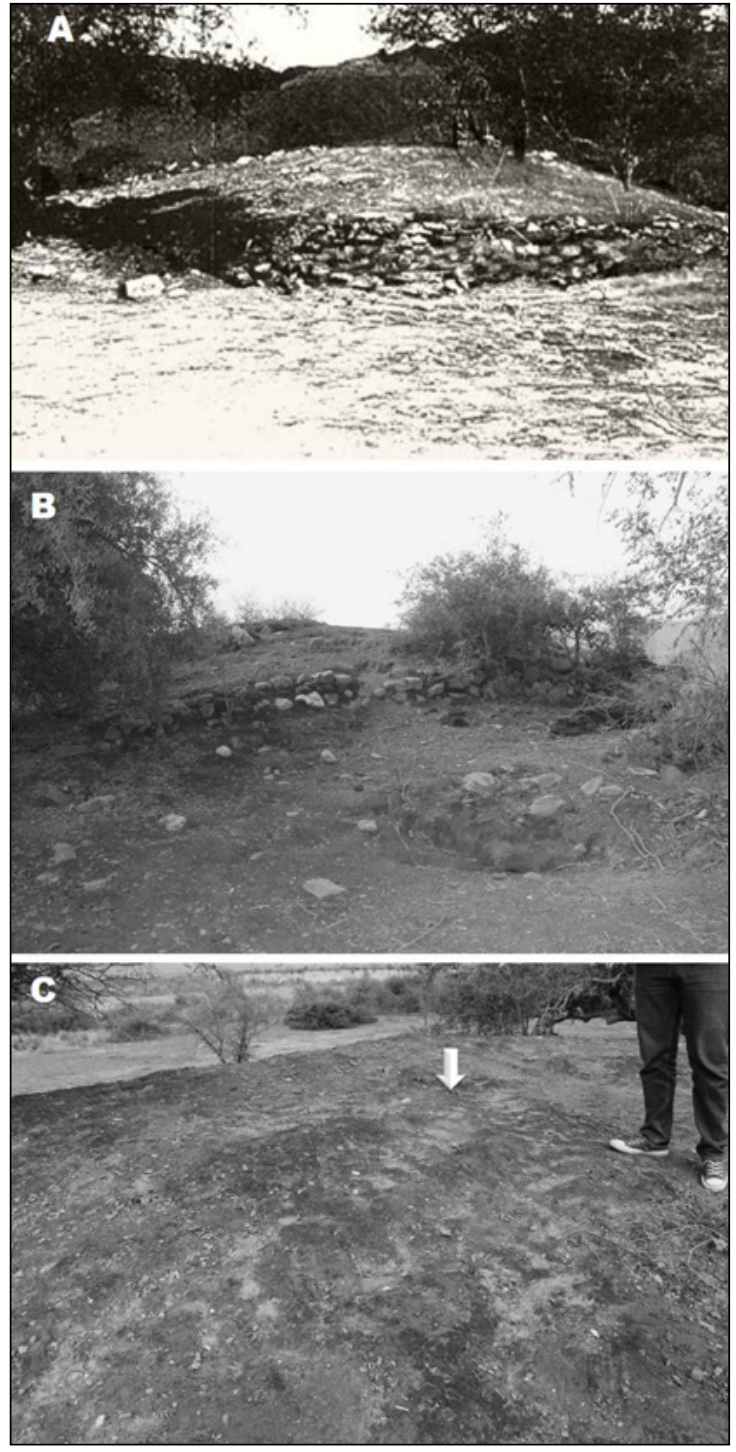

Figura 2. Montículo de La Rinconada o Iglesia de los Indios: A) y B) visuales del montículo-plataforma y, C) huella de tractor en la cima de la plataforma.

vestigaciones en el lugar (Pérez Gollán y Heredia 1975). Montículos de este tipo habían sido registrados y excavados en otras regiones aledañas al Noroeste Argentino (NOA), como es Tafi del Valle -montículo El Mollar (González 1977) - o los sitios de Alamito (Núñez Regueiro 1998).3 En los primeros años de investigaciones en el

3 En el caso de Alamito se han hallado en tres terrazas aluviales, a diferentes alturas, una serie de unidades que tienen forma de anillo compuestas por una depresión central, rodeada por una serie de montículos. Estas estructuras no son todas iguales sino que una de ellas es un montículo más grande que el resto. Uno de 
valle de Ambato, se empezaron a excavar dos de los montículos, uno denominado El Altillo, cercano a la localidad de Los Castillos, y otro ubicado más al suroeste del valle, denominado Martínez 3. El Altillo, hasta el momento, es

los montículos excavados posee $3 \mathrm{~m}$ de alto por $47 \mathrm{~m}$ de longitud y $36 \mathrm{~m}$ de ancho, se halla rodeado por su lado oriental de una pared de contención realizada con rodados superpuestos dejando un lienzo disparejo. El relleno se componía de variedad de objetos, gran cantidad de fragmentos cerámicos, huesos de animales fragmentados -algunos quemados-, abundantes desechos líticos, lentes de cenizas, espículas de carbón, huesos y un cráneo humano; por estos hallazgos a estos montículos los llamaron "basureros" (Núñez Regueiro 1998: 253). En Tafi del Valle, se ha hallado otro conjunto de montículos que son más tempranos que los de Alamito, pero que en cierto momento son contemporáneos. Estas estructuras están compuestas fundamentalmente por rocas pequeñas y medianas. Sus dimensiones varían desde 30 a $40 \mathrm{~cm}$ de altura hasta $4 \mathrm{~m}$ de alto y decenas de metros cuadrados de extensión. En estos últimos casos se encuentran a veces estructuras simples pequeñas construidas en superficie. Son en general resultado del despedre de los campos previos al cultivo, y en ocasiones han sido empleados a su vez como basurales (como se desprende de la abundancia de fragmentos cerámicos y líticos en superficie) (Berberián y Nielsen 1988: 30). Estas estructuras están asociadas a sitios del típico patrón margarita (Rafino 1988) que Berberián y Nielsen (1988) denominan unidades circulares compuestas, que constan de uno o más recintos circulares grandes (a cuyos muros se adosan uno o más recintos circulares pequeños o medianos). También estos montículos se asocian a varios de estos tipos de estructuras que conforman una especie de aldea. Uno de ellos, el más grande denominado El Mollar, arrojó una fecha muy temprana $2296 \pm 70 \mathrm{AP}$, es decir al inicio del Período Formativo del NOA. Al parecer este montículo se hallaba rodeado por un tipo especial de esculturas líticas -menhiressituados alrededor del mismo. González (1977: 108) interpreta esta conformación arquitectónica como centro ceremonial que en determinado momento del año debió congregar, en ritos y ceremonias, buena parte de la población del valle y de las zonas aledañas. Ampliando la mirada a la región sur andina, encontramos estructuras monticulares de características similares, que fueron asociadas a la producción de espacios y paisajes monumentales. El caso de los túmulos de los valles de Azapa en Chile, de momentos del Período Intermedio Temprano, muestran la producción de estos montículos como monumentos. Si bien existen divergencias en la interpretación de los mismos, es sugerente la propuesta de Álvaro Romero et al. (2004) de que la serie de rituales realizados en estos lugares (entierros y ofrendas), más que denotar el poder o prestigio de la persona enterrada, podrían considerarse como ofrendas al mismo montículo. Es decir, las transformaciones que se producen en las sociedades en ese momento son procesadas cultural e ideológicamente mediante la producción de estos monumentos. el sitio más antiguo hallado en el valle, posee un fechado de alrededor de 1900 AP (Laguens y Bonin 1996; Marconeto et al. 2014). Es decir, las prácticas de acumulación de desechos en estos sitios se realizan desde comienzos de la ocupación en el valle. A pesar de que El Altillo, el primer montículo excavado, se halla aislado de otras construcciones, tempranamente los arqueólogos que investigaron la zona observaron que en general estas estructuras están estrechamente asociadas a las viviendas, de donde provendrían los desechos arrojados a ellos (Ávila y Herrero 1991; Assandri 1991; Juez 1991; Herrero y Ávila 1991).

La estrecha vinculación que existe en el valle entre las casas y los montículos, fue enfatizada hace casi dos décadas por Haber, Laguens y Bonnin en un trabajo corto pero programático denominado "Montículo y casa. Elementos retóricos en la cultural material Ambato", expuesto en la mesa redonda sobre Cultura de la Aguada (Haber et al. 1996-97). Nuestro trabajo retoma algunas de las postas dejadas por los autores en este artículo, las que pasaremos a analizar ahora.

Los autores, influidos por lo que se conoce como giro lingüístico en arqueología, pretendían en ese trabajo más que narrar o interpretar la cultura material Aguada, comprenderla como una narración o interpretación en sí misma (Haber et al. 1996-97: 59). En este sentido se acercaban a la idea de que toda interpretación arqueológica, histórica o antropológica es en sí una interpretación de una interpretación, acercándose a los planteamientos de Paul Ricoeur ${ }^{4}$ y en cierta forma retomando la antropología interpretativa de Geertz (1992). A nivel metodológico, influidos por la arqueología contextual (Hodder 1988), la asociación y contraste entre objetos y contextos era la principal herramienta metodológica aplicada para construir la narrativa histórica del valle. Esta narrativa señalaba que se podía comprender la historia del primer milenio de la era en la zona valliserrana del NOA

...como una sucesiva acumulación de experiencias narrativas, elaboración de nuevos mensajes y su ampliación hacia nuevos aspectos de la realidad. No se trata de reemplazos sino de acumulaciones. Es como una lenta y continua depositación de capas de sentido que, inevitablemente, cambian por su peso, el sentido de las capas anteriores (Haber et al. 1996-97: 60).

4 Para una incorporación de la teoría de Ricoeur en arqueología, ver Moore (1990). 
Haber, Laguens y Bonnin proponían, para la historia del primer milenio del valle, la existencia de dos modalidades narrativas en las que la cultura material y la experiencia se vinculaban en formas diferentes: en un primer momento (siglos I a IV o V DC) un conjunto de disposiciones parecen girar en torno a la idea de casa y otro en torno a la de montículo. La casa para los autores encerraba la idea de la domesticación, lo cultural, lo cotidiano, la producción y la reproducción social. Esas características se manifestaban en la arquitectura doméstica, la presencia de fogones, de restos de alimentación, y la aparición de las vasijas en el interior de las viviendas (1996-97: 60). Una segunda matriz conceptual abarcaba algunos elementos que quedan para estos autores fuera de la casa, que se hallaban presentes en los montículos o "allpataucas": "la muerte como opuesto a la vida, lo salvaje como opuesto a lo doméstico, quedaba tanto fuera de la casa como sugerido (si no expresado) en los montículos" (Haber et al. 199697: 60). Los montículos eran definidos como parte de un amplio espacio conceptual abierto a la ambigüedad, en donde lo humano puede mezclarse con lo animal, con lo salvaje, como en las figuras antropomorfas Condorhuasi de frecuente aparición en los montículos más tempranos. Para estos autores la cerámica Condorhuasi, que se presenta en general vinculada en distintas partes del NOA a contextos funerarios, parece connotar la muerte con un sentido de ambigüedad (Haber et al. 1996-97: 60). La aparición en estos lugares de grandes acumulaciones de desechos como cerámica rota, restos de vegetales, huesos de animales y humanos, les induce a pensar que esa matriz conceptual no solo estaría en las tumbas sino en los montículos. A su vez, señalan que estos montículos de $304 \mathrm{~m}$ de alto, que no se hallan delimitados, probablemente correspondan a lugares destinados a otras cosas, a ofrendas, y es posible que su acumulación se origine en la reiterada acumulación de depositaciones. A pesar de esta vinculación con lo salvaje, la muerte, lo no domesticado, Haber, Laguens y Bonnin señalan que estos espacios no niegan lo doméstico, por cuanto la apariencia de depositación de desechos domésticos retiene el carácter ambivalente de lo cotidiano junto con lo que se sale de lo cotidiano (Haber et al. 1996-97: 60).

En un segundo momento, la aparición o consolidación en la historia local de lo que se conoce como cerámica Aguada, a partir del siglo V o VI DC, con su profusa iconografía vinculada con el felino, sacrificadores, mezclas de humanos y no humanos, etcétera, les sugiere que existe una incorporación de la muerte en el ámbito doméstico. ${ }^{5} \mathrm{Si}$ uno recorre los diferentes contextos arqueológicos pertenecientes a esos momentos, puede observar la presencia de restos humanos fragmentados al interior de las viviendas, así como de entierros (Cruz 2005; Gastaldi 2013; Gordillo y Solari 2009; Juez 1991; Herrero y Ávila 1991; Laguens y Gastaldi 2008). Para Haber et al. (1996-97), lo que estaba fuera de la casa, excluido en montículos o cementerios, es incorporado a la vida diaria, la muerte comienza a convivir en el ámbito de lo doméstico. Para los autores, en ese momento, en el valle existe una expansión de la idea de casa en tanto que a los montículos se los reinterpreta en términos de arquitectura, se los comienza a delimitar mediante su inscripción entre muros de piedra, un mismo tipo de lenguaje que emplearon en la delimitación de los espacios domésticos. Este planteamiento de los autores es claramente observable en el sitio La Rinconada (Gordillo 2009), donde a un antiguo montículo basurero se le construyen paredes y es transformado en una plataforma que corona un espacio público rodeado de viviendas. ${ }^{6}$ Esta observación los lleva a sugerir que “...si en un momento pudo haber habido una tensión entre el montículo y la casa, en un segundo momento el lenguaje elaborado a partir de lo doméstico expande su aplicación hacia el espacio común público" (Haber et al. 1996-97: 60). La delimitación e incorporación de los montículos al espacio ritual común, enfatizaría el lenguaje de lo doméstico que se ha vuelto aún más fuerte, pero es elaborado ahora como metáfora del grupo social: “...la creación de unidades sociales mayores utiliza la metáfora de la casa,

5 En el siglo IV o V DC en el valle, se identifican ciertos cambios en las clases tecnológicas cerámicas; por una parte, existe una reducción en la cantidad de 42 a 12 y por otra, la popularización de otras clases que se producen desde los primeros años del primer milenio DC. Las clases tecnológicas $\mathrm{Al}$-negra gris grabada- y la clase $\mathrm{E}$-vasijas toscas para cocinar y las grandes vasijas tricoloraumentan su proporción, la primera en un 30\% y la segunda un 100\%-. En el caso de la clase $\mathrm{Al}$, si bien a nivel tecnológicos de pasta, cocción, lugares de fabricación no cambia, sí hay cambios en la iconografía, se le incorpora todo el repertorio Aguada (Fabra 2008; Gastaldi 2010).

6 Gordillo (2009) señala que las paredes de la plataforma de La Rinconada (llamada Iglesia de los Indios por los pobladores locales), se realizaron sobre un antiguo montículo basurero, producto de arrojar basura de las habitaciones que forman el sitio. Probablemente, los desechos podrían provenir de la estructura 23 , que es una de las más antiguas de la Rinconada. 
tal vez transportando hacia la unidad social mayor las connotaciones que la casa tenía en relación a la familia en términos de referencia individual, en fin ámbito de constitución del individuo" (Haber et al. 1996-97: 60).

Encontramos en esta breve síntesis del trabajo de estos autores, tres aspectos relevantes para retomar, en tanto nos permitirán avanzar y profundizar en el modo en que las prácticas de limpieza observadas en el sitio Piedras Blancas, y su vinculación con la formación de los montículos basureros, nos permiten comprender mejor el proceso mediante el cual, en la ejecución de la limpieza, las unidades sociales que habitaban la casa se definían a sí mismas y definían el universo colectivo mayor al cual se ligaban a nivel de todo el valle. En primer lugar, retomaremos los conceptos de sedimentación y acumulación propuestos para narrar la historia del valle y del área valliserrana. Estos conceptos nos servirán para pensar en cómo el montículo en sí mismo conforma un proceso de acumulación y sedimentación de sentidos y tiempos, experiencias vividas en la casa, que permiten el establecimiento de memorias colectivas de largo plazo. En segundo lugar, la idea de ambivalencia del montículo, como espacio que sale de lo cotidiano pero retiene su génesis doméstica, nos abre el camino para considerar el montículo como espacio monumentalizado y re-monumentalizado, que permite a las unidades domésticas entablar un diálogo con la comunidad mayor en sus propios términos, definidos por ellas mismas. Si esos montículos, según lo que proponían Haber et al. 1996, debieran ser pensados como textos o narraciones en sí mismos, se trataría de especies de autobiografías de grupos domésticos, de esas casas, escritas en el espacio más común donde se emplazan los montículos. La ampliación de la idea de casa que surge en el segundo momento, es decir, a partir del siglo IV o V DC, expresa esta situación y marca lo doméstico, la idea de casa y el montículo como metáfora de formación de grupos sociales mayores.

\section{* El monumento y los Sedimentos:}

MEMORIA, EXPERIENCIA Y PAISAJE

Monumento es una categoría que desde la arqueología, y desde hace no mucho tiempo, ha sufrido resignificaciones profundas, transformándose en una fuente de discusión teórico-metodológica para el abordaje de temas vinculados a la construcción de las memorias sociales en el pasado, así como también a la construcción en el presente de memorias de grupos subalternos, tales como minorías étnicas, políticas, etcétera (Criado Boado 1989, 1991; Haber 2006, 2011a, 2011b; Olsen 2010; Thomas 1996, 2011; Tilley 1994). En el caso del contexto latinoamericano, y específicamente en Argentina, el monumento como dispositivo físico y duradero, no solo fue utilizado por los Estados-nación en la construcción de una memoria nacional universal, sino que también se ha transformado en uno de los dispositivos materiales que permitió una lucha en el plano de los procesos de disputa hegemónica por el sentido común del pasado reciente vinculado a la tortura, asesinato y desaparición de personas durante la dictadura militar de los años setenta y principio de los ochenta (Funari y Zarankin 2006). En otro plano, la emergencia de grupos étnicos ha tomado los monumentos como dispositivos que afianzan relaciones con sus antiguos lugares de pertenencia (Curtoni y Chaparro 2008; Endere y Curtoni 2006).

El monumento, en general, ha sido interpretado como un acto de fundación, un acontecimiento que se configura en estructurador de prácticas futuras. Al ser altamente visible y duradero está orientado hacia el futuro. Criado Boado (1991) señala, cuando analiza el megalitismo europeo, que una de las características de las tumbas megalíticas es precisamente ser monumento: construcción de grandes proporciones concebida para resistir el tiempo, y ser visible, resaltar en el espacio circundante. Para el arqueólogo español, lo importante del megalito, es la articulación que realiza del monumento con el tiempo y el espacio, haciéndose visible y duradero en uno y en otro (1991: 93). Así el megalito, como monumento originado en generaciones pasadas, naturaliza la genealogía de las generaciones del presente. En el caso de los montículos, a diferencia de los megalitos, se trata de monumentos visibles y duraderos, pero cuyas propiedades, más que concedidas por un evento fundacional -un acontecimiento-, como puede ser la construcción de un megalito, fueron adquiriéndose paulatinamente a través de un proceso de sedimentación y acumulación.

La sedimentación como proceso - no solo estratigráfico en el sentido físico del término, sino simbólico-y su participación en la formación de monumentos, ha sido una categoría que en la arqueología argentina comenzó a ser discutida para analizar la formación y estructuración de 
los paisajes indígenas campesinos de los oasis del primer milenio DC, en la puna de Atacama (D'Amore 2007; Gastaldi 2007; Haber 2006, 2011b; Haber y Gastaldi 2006; Quesada 2009).

Haber (2011b: 26) señala que la sedimentación es una forma cultural que reduce la sincronía social a una "sucesión natural". Consiste en la depositación de objetos vinculados con la apropiación que la gente realiza de la "naturaleza", de manera tal que cada sucesión se superpone a otras anteriores, y solo de algunas se conserva memoria, llegando a formar en ocasiones verdaderas estratigrafías (Haber 2011b: 26). Para este autor (2011b: 27), las sendas temporales de la cotidianidad y las biografías individuales - agregaría a estas biografías de personas, las de los objetos, tal cual las hemos desarrollado en otras investigaciones (Gastaldi 2007, 2010; Haber y Gastaldi 2006) - se inscriben en series diacrónicas de un tiempo más largo, materializadas en eventos similares de depositación.

El sedimento, para Haber, es la forma cultural que más persuasivamente produce un paisaje doméstico, en tanto inscribe la rutina cotidiana en una serie estratigráfica cuyo origen y muy probablemente su fin, se encuentran fuera del contexto de reproducción de la rutina (2011b: 27). La sedimentación como categoría es un concepto muy potente para desnaturalizar los paisajes arqueológicos; permitiendo pensarlos como en continuo proceso de formación y acumulación de tiempos y significados históricos específicos.? Retomando este concepto, nos acercamos a la definición que diera Ingold (1993) sobre el paisaje: una red de tiempos interrelacionados y ritmos temporales, definiéndolo como una compleja composición de ciclos y cronotopos. Nuestro ser-en-el-mundo para este autor, es ya una experiencia híbrida de diferentes referencias temporales. En el mismo sentido dado por Ingold, Olsen (2010: 108) señala que en cada momento lo material del mundo nos confronta con un gran patchwork de horizontes temporales coexistentes, que crean redes y conexiones entre diferentes tiempos, diferentes

7 La sedimentación, como categoría teórica, surge como foco de estudio principalmente en la arqueología inglesa; por ejemplo Bender (1993) la recoge para pensar la construcción del paisaje de Stonehenge. Se puede observar también este planteamiento en Tilley (1994) para comprender la condensación de significados a nivel de los paisajes desde un punto de vista fenomenológico y de la experiencia. pasados. Ambos autores de cierta manera se acercan a lo que señalaba Halbwachs (2004), cuando se refería a la memoria colectiva, que el entorno material lleva al mismo tiempo nuestras marcas y la de los otros. En ese sentido, observó que no existe una memoria colectiva que no se desarrolle en un marco espacial. En el espacio, según este autor, nuestras impresiones se suceden unas a otras. En arqueología diríamos que conforman verdaderas estratigrafías (Carandini 1997); capas que se sedimentan unas sobre otras y narran la apropiación que la gente realizó de ese espacio en el pasado (D'Amore 2007; Haber 2006, 2011b; Gastaldi 2010, 2012). De esta manera, como bien lo señala Halbwachs (2004), nada permanece en nuestro espíritu y no sería posible comprender o recuperar nuestro pasado si no se conservase en el medio material que nos rodea. Todas estas perspectivas dirigen la atención a pensar los procesos de memorialización y subjetivación de las personas, menos como una representación y más como experiencias vividas y actuadas (Ingold 1993; Olsen 2010; Thomas 1996; Tylley 1994). Así, para estas perspectivas, el presente no estaría compuesto por cosas que pertenecen a una edad; tomaría la forma de un campo multitemporal en el cual el pasado se ha ido acumulando a sí mismo (Olsen 2010: 108). La cultura material, pensada de esta manera, más que ser trazos o residuos de presentes ausentes, está efectivamente inserta en épocas y períodos híbridos y mezclados (Olsen 2010: 108). ${ }^{8}$

Si pensamos en los montículos como procesos de sedimentación y acumulación de "residuos", podríamos definirlos en este sentido como espacios multitemporales, híbridos y mezclados. La sedimentación como proceso de formación de estos lugares produce la acumulación de materiales y residuos que provienen y conviven en distintos tiempos (Gastaldi 2010, 2012). Ese mismo proceso, que es acumulativo, lo va tornando altamente visible en el paisaje, haciéndolo participar de lleno en el presente contingente, y a su vez lo enraíza a un pasado remoto. Los residuos, a medida que son arrojados, en un proceso de temporalidad prolongada (algunos montículos son utilizados por varios siglos), se van transformando paulatinamente en sedimentos, en tierra; su largo proce-

8 Esto no quiere decir que no existan cosas que pertenezcan a un presente más inmediato, lo que sí señala es que el presente está articulado también por las cosas del pasado. Tanto las inmediatas como las anteriores conviven en el presente. Las prácticas sociales se dan en esos contextos híbridos y multitemporales. 
so de acumulación da la sensación de que siempre estuvieron allí. Como discutiera Ingold (2013: 75-77) sobre estructuras monticulares semejantes: no se erigen sobre el terreno, como lo pensaría un arquitecto que pretende diseñar un monumento, ni siquiera se fabrican de una sola vez, crecen desde la tierra; los residuos de hoy se vuelven sedimentos mañana, lo que arrojamos en la cima se desliza hacia abajo, se mezcla con los sedimentos, se transforma en alimento de la tierra, del suelo. El límite entre el suelo y el montículo tiende a desaparecer, le crece hierba, desdibujando su factura artificial. Este autor dirá:

El suelo, al fin, es un devenir continuo que se desarrolla con sus habitantes. Como el tejido de las plantas y los cuerpos de los animales, el conocimiento hace crecer el suelo de lo social; como los habitantes siguen sus propios caminos, continuando el de sus predecesores; el suelo y el conocimiento que crecen de él, están siempre en formación y nunca terminados (Ingold 2010: 136).

\section{* Alimento de la tierra, fábrica de suelo: las CASAS Y LOS MONTÍCULOS EN PIEDRAS BLANCAS}

En este acápite se analizará un caso específico, el sitio Piedras Blancas (una casa-montículo). Concretamente describiremos las prácticas de limpieza de los pisos de las habitaciones, y cómo éstas se vinculan con la creación y fabricación de los montículos.

Piedras Blancas (Figura 1) es un sitio de vivienda, que posee $100 \mathrm{~m}$ en dirección este-oeste y $80 \mathrm{~m}$ en sentido norte-sur, conformando un rectángulo. Al sitio se ingresa por el oeste. A unos $15 \mathrm{~m}$ de la entrada, por fuera de él, se erige un montículo basurero, ahora aplanado por las actividades agrícolas pero que originalmente sobresalía 2 a $3 \mathrm{~m}$ de la superficie, y tenía 15 a $20 \mathrm{~m}$ de diámetro. El ingreso al sitio está flanqueado por dos muros confeccionados de tapia o adobe y columnas de piedras, revocado del lado interior con un estuco color rojo y del lado exterior con cuarzo blanco. Digamos que quien ingresa al sitio, pasa al lado del montículo y lo hace por esa puerta que resalta del resto del lugar, en tanto es el único muro decorado de esta forma. Una vez traspasada la entrada delimitada por ambas paredes forradas en cuarzo, se penetra a un patio central que se encuentra más hundido. Desde este punto central se puede acceder a otros espacios de la vivienda: a otros patios, galerías y habitaciones techadas. Las excavaciones se realizaron en distintos sectores del sitio (Figura 1). Poseemos una estratigrafía más detallada del sector suroeste del sitio, donde se excavó un recinto completo (RF), su galería adosada y parte del patio (Figura 3). En total, en dicho sector se excavaron aproximadamente $100 \mathrm{~m} 2$

Para su excavación se siguieron los lineamientos de Harris (1991), que permiten una reconstrucción precisa de la estratigrafía del depósito excavado y para quien el objetivo de la excavación arqueológica es llegar a reconstruir la matriz estratigráfica. La secuencia estratigráfica está formada por unidades estratigráficas, que se consideran la unidad elemental de excavación y análisis. Éstas, a su vez, representan una acción o un conjunto de acciones que pueden ser naturales o culturales (Ibíd.). Estas acciones o conjunto de acciones, como unidades mínimas, se ordenan secuencialmente a través del principio estratigráfico de subyacencia o suprayacencia, que permite identificar qué acción se realizó primero y cuál después (Ibíd.). Por tanto, la secuencia reconstruida nos brinda una narrativa de las acciones que dieron forma a este espacio (D'Amore 2007). ${ }^{9}$ Establecer la secuencia estratigráfica nos posibilitó reconstruir los procesos de sedimentación. A su vez, la aplicación de esta metodología, que implica una interpretación reflexiva continua durante el proceso de excavación (Hodder 1997), es la que permitió identificar la recurrencia de la limpieza de los pisos, ejecutada por los habitantes de Piedras Blancas. ${ }^{10}$ Se describirá a continuación la matriz estratigráfica obtenida de la habitación RF, que permitirá profundizar el análisis de dichas prácticas de limpieza.

\section{Coreografía de la limpieza}

Barriendo el piso: recogiendo la materia fuera de lugar. RF es un recinto techado de unos $6 \times 7 \mathrm{~m}$ de ancho. Posee una entrada de unos $0,90 \mathrm{~m}$ de ancho que lo comunica a un patio y a una galería. Esta última tiene $2 \mathrm{~m}$ de ancho y corre en sentido norte-sur y se encuentra adosada al muro

9 Para la aplicación de los principios de estratigrafía de Harris se siguieron los lineamientos del Servicio de Arqueología del Museo de Londres, Spence (1994).

10 En un trabajo anterior, analizamos este proceso de reflexividad señalado por Hodder (1997) en la excavación del sitio de Piedras Blancas, ver Gastaldi (2012). 


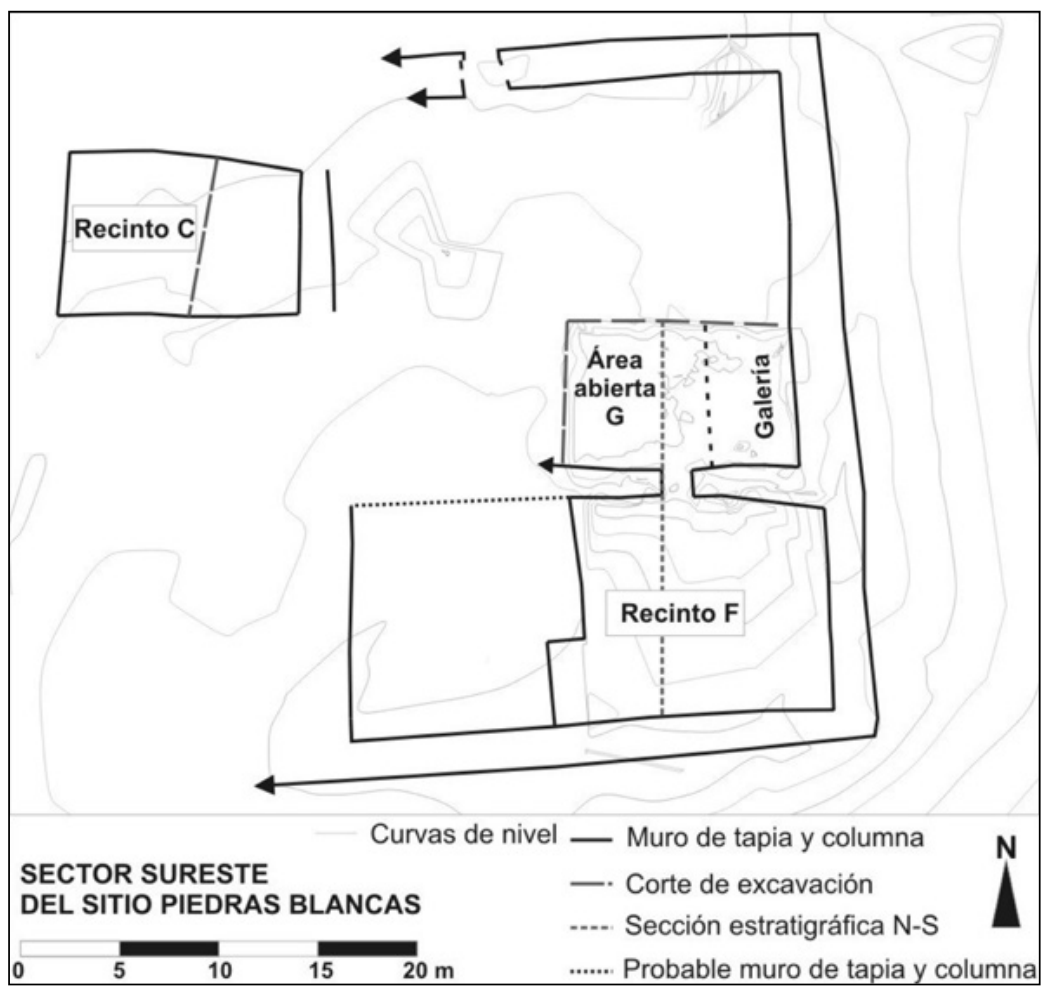

Figura 3. Plano de detalle del sector suroeste del sitio Piedras Blancas.

perimetral este. Este muro es de $0,70 \mathrm{~m}$ de ancho, confeccionado con la técnica de tapia y columna. ${ }^{11}$

El piso del recinto se encuentra a o,20 m por debajo del patio, por lo que para ingresar a la habitación se debe bajar un peldaño. El recinto $F$, hacia el oeste posee otra estancia adosada de características semejantes. Si uno sale de él hacia el exterior y atraviesa el patio dirigiéndose hacia el norte, se encuentra con dos recintos más, que por las prospecciones geofísicas realizadas tendrían las mismas características que RF.

En la excavación de RF se definieron en total 56 unidades estratigráficas (Figura 4). En su interior se identificaron: rellenos por erosión y acumulación eólica, derrumbes de muros de tapia y columnas, y además, al igual que en varios sitios excavados en el valle, se encontró la techumbre incendiada y derrumbada [8]. Por toda la superficie del recinto se extendían las vigas de troncos principales

11 La técnica de la tapia usada en el valle de Ambato implica la realización de un encofrado y el apisonado de capas de tierra húmeda, formando módulos alternados por columnas de piedras. y secundarias; también apareció la enramada (Figura 5 y Figura 6A y 6B). A medida que se fue extrayendo esta unidad estratigráfica, definida como derrumbe de techumbre incendiada, y se fueron retirando los troncos carbonizados, se observó que éstos estaban aplastando objetos enteros o casi enteros, estructuras de piedra, fogones, etcétera; además, estos objetos se encontraban apoyando en el piso [10], una superficie muy consolidada (Figuras 5, 6F y 7 ).

En el sector sur de la habitación (Figura 6C y 6E) aparecen sobre el piso [10], aplastados por el derrumbe de la techumbre, una vasija de cerámica globular con huellas de carbonización (B52), una pipa, una pelvis de camélido, placas de mica, un puco rojo completo totalmente fragmentado, otro puco de color negro gris grabado, una segunda pipa rota y dos cucharas de madera fragmentadas. En el mismo sector y hacia el centro del recinto, por debajo del techo incendiado [8], se hallaron una serie de fogones pequeños -[18], [22], [29](Figura 7). Las cubetas de los fogones se excavaron en el piso [10]-[19], [21], [33]-. Además, se identificó un estrato de ceniza que correspondería a la limpieza de 


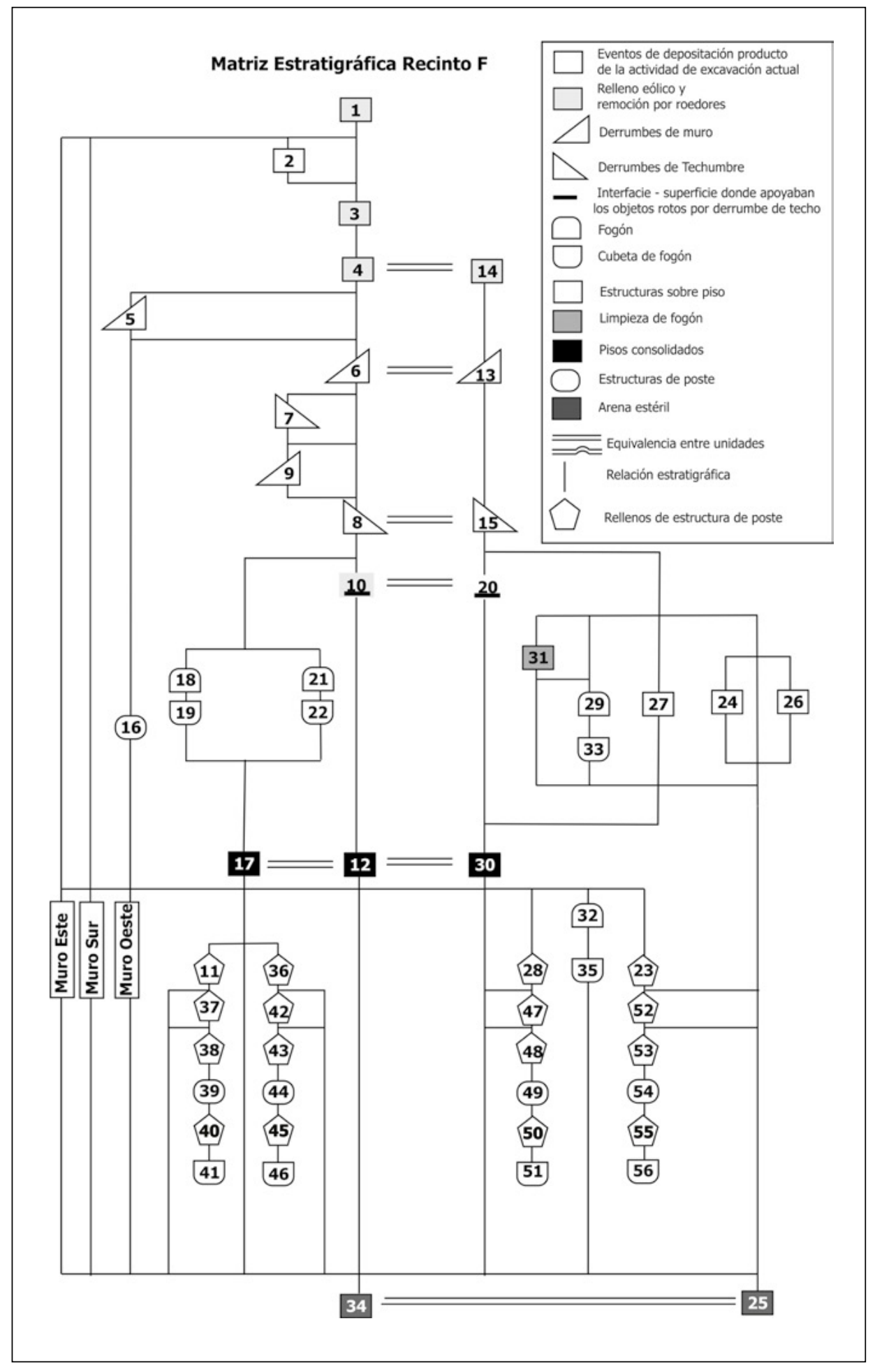

Figura 4. Matriz de Harris del Recinto F. 


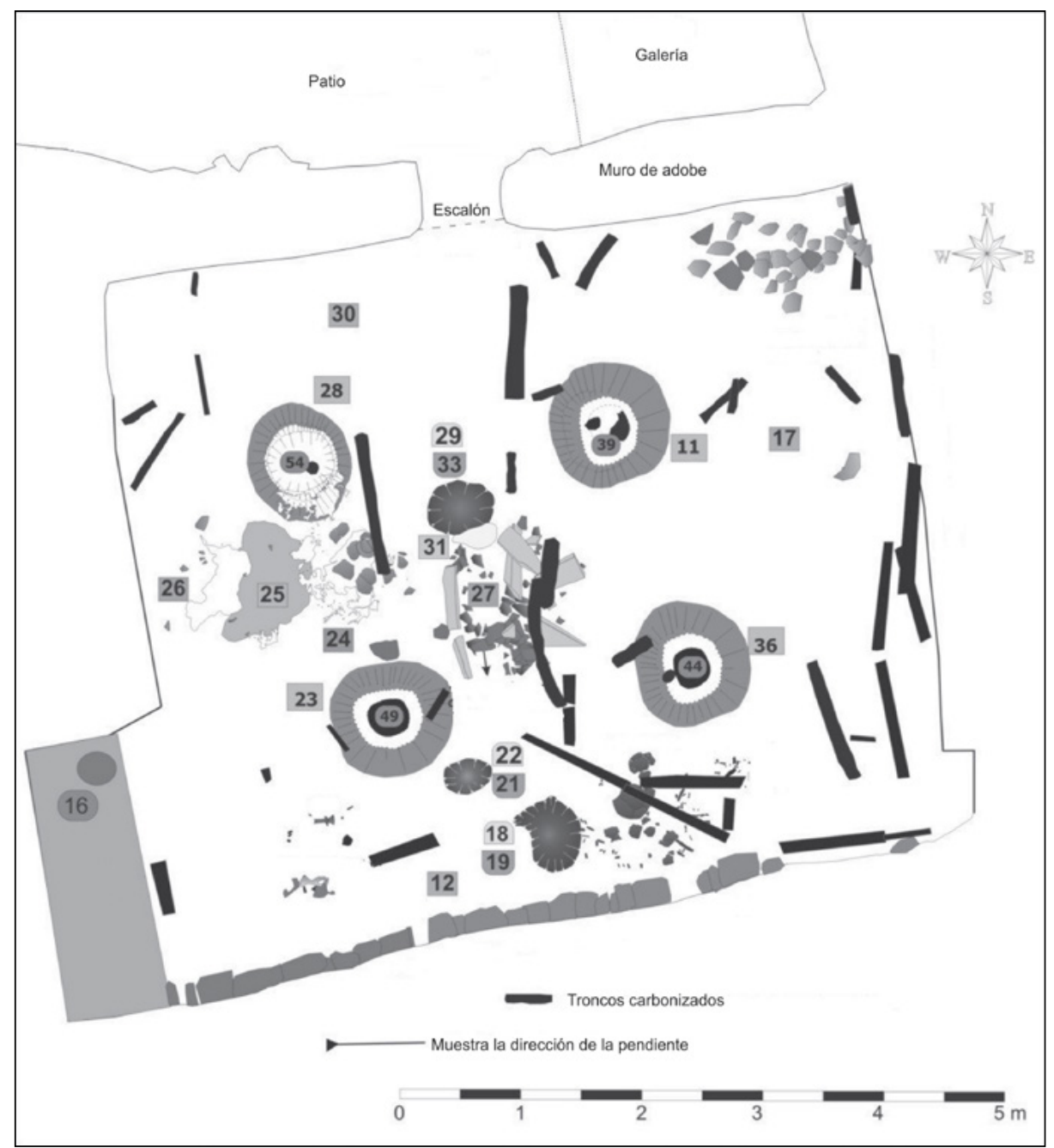

Figura 5. Planta compuesta de excavación del Recinto F.

uno de estos fogones [31]. También en el sector central, apoyada en el piso [10] y aplastada por el techo, se halló una estructura de piedra [27] que contenía en su interior una vasija casi completa y un puco negro gris grabado, entero pero fragmentado (Figura 6D). En el sector oeste, casi contra el muro de tapia con columnas, apoyados en el piso [10], se identificaron dos contenidos de vasijas, y las propias vasijas que los contenían todas fragmentadas. Estos rellenos, según los análisis de pigmentos, eran de pintura de color blanco en estado líquido (Galván et al. 2010) -[24] y [26]- (Figura 5). También se hallaron por debajo de la techumbre [8] cuatro estructuras de sostén de poste -[39], [44], [49] y [54]- (Figuras 5 y 7). Estos hallazgos aplastados por el techo y que se están apoyando en la superficie con- solidada [10], luego de ser levantados y al comenzar a excavar dicho estrato, generaron ciertos interrogantes: ¿A cuál estrato debían asociarse los objetos que habían sido aplastados por el derrumbe del techo y que se hallaban apoyando en [10]? Si se seguían los lineamientos de la excavación por unidades estratigráficas propuestas por Harris (1991), los objetos debían ser asociados al estrato donde se apoyaban, es decir a [10].

En este método de excavación, la unidad estratigráfica, definida como una acción o conjunto de acciones, es la unidad de análisis y, por lo tanto, de sentido. Los objetos se toman como inclusiones de ellas. Teniendo en mente esto, si se consideraba como inclusiones de [10], tanto los objetos que apoyaban en su superficie, como aquéllos 

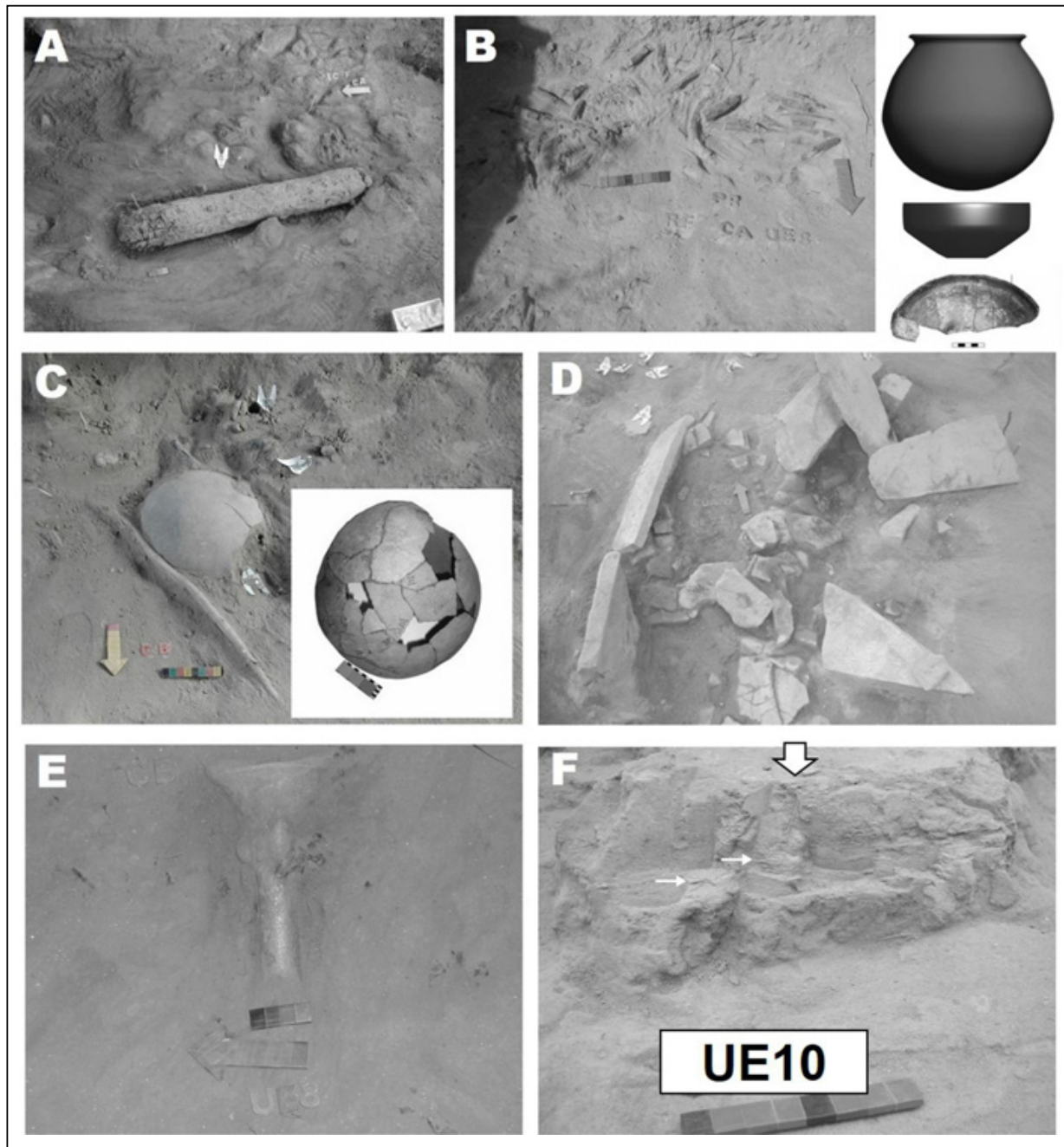

Figura 6. Distintos contextos del Recinto F del sitio Piedras Blancas: A) tronco de viga carbonizado; B) enramada del techo carbonizada; C) vasija globular con huellas de carbonización; D) estructura de piedras de contención de vasijas - las piezas halladas dentro de la estructura se muestran arriba de esta imagen-;

E) pipa de cerámica; F) corte del piso [10].

que comenzaron a aparecer al comenzar a excavar [10] que a diferencia de lo que hasta el momento fue hallado, corresponde a fragmentos cerámicos más pequeños que no remontaban entre sí y a escasos restos óseos y líticos), surgían otros interrogantes: ¿No se estarían creando relaciones significativas entre objetos que quizás no las tenían?, ¿no se estarían perdiendo otras relaciones quizás más significativas que hubieran tenido estos objetos apoyados en [10] con las otras unidades estratigráficas apoyadas en [10] (estructura de contención de vasijas, fogones, vasijas con pintura líquida, etc.)? Durante la excavación se tomó la siguiente decisión: separar estos hallazgos (los fragmentos pequeños que surgieron al comenzar a excavar [10]) y asignarlos como inclusión de otro estrato [12]. La unidad [10] (Figura 8) pasó a conformar la superficie o interfacie -sensu Harris (1991)- de apoyo de aquellos materiales (vasijas, ollitas y pucos casi enteros, pipas etc.) que fueron aplastados por el techo. Así, la unidad [12] pasó a conformar el piso consolidado, es decir, el lugar que le había sido otorgado con anterioridad a la unidad [10].

Harris (1991) define las interfacies como la superficie de las unidades estratigráficas, y es uno de los elemen- 


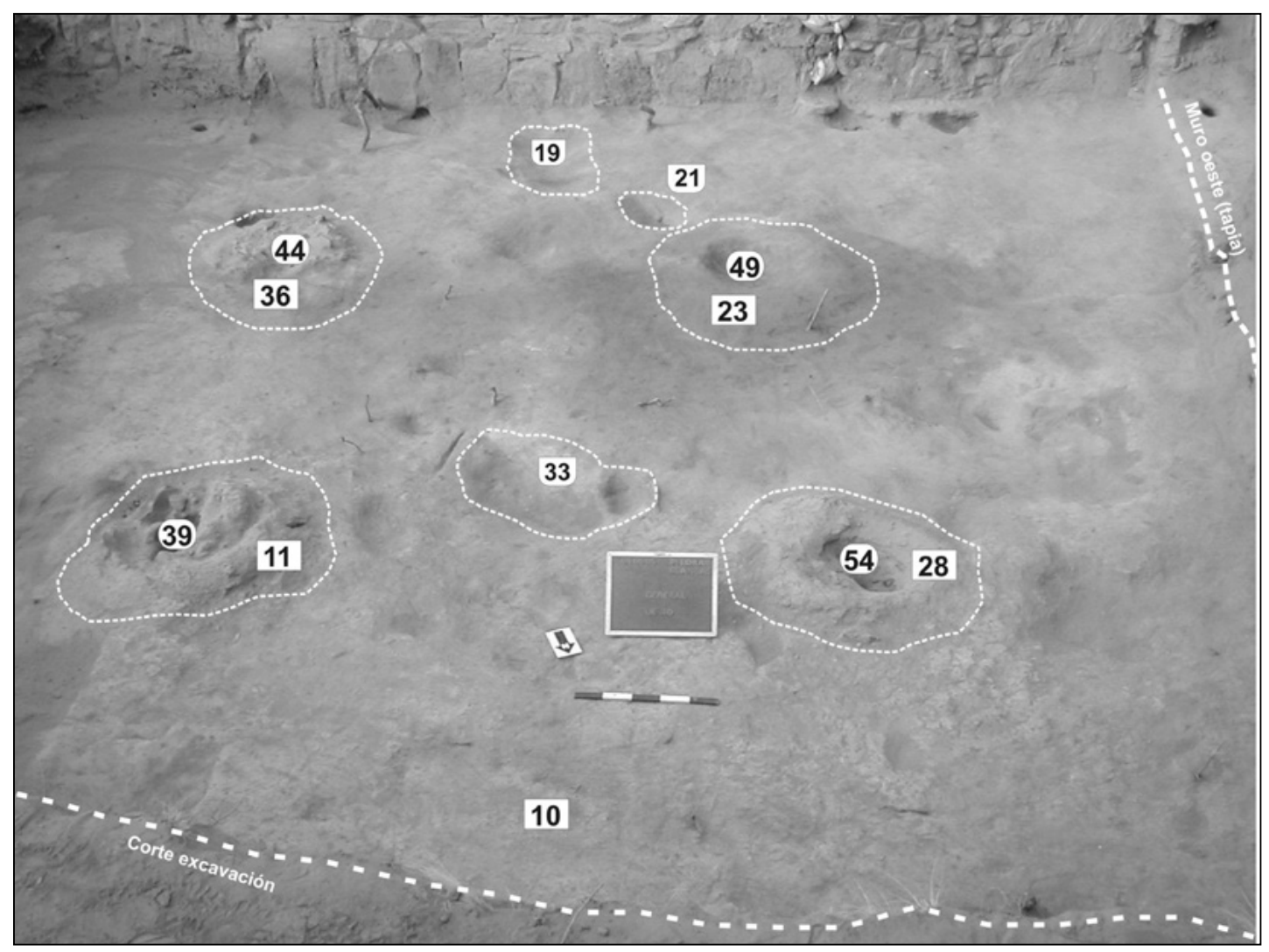

Figura 7. Vista general de la unidad [10] y distribución de contextos.

tos más importantes para identificarlas. Las interfacies conforman aquello que permite dividir la tierra en dos, diferenciar dos acciones o conjuntos de ellas y establecer las relaciones estratigráficas. Cuando un grupo de estas interfacies conforma una gran superficie, se habla de interfacies de período, que nos indican un momento específico de uso coetáneo. Teniendo en cuenta esto, [10] conformaría la interfacie de estrato de [12], que junto con las interfacies de estrato de [27], [26], [24], [18], [21], [31] y [29], constituirían una interfacie de período, a la que deberían sumarse las interfacies de estrato vertical de los muros sur, norte, este y oeste que delimitan el recinto, y también la interfacie de estrato formada por la superficie del techo que se derrumbó y aplastó los objetos (Figura 8, línea entrecortada). En este sentido, [10] marca un tiempo y un espacio de uso común y coetáneo. No se sabe el tiempo en el que los objetos apoyados en el piso o almacenados en la estructura de piedra, fueron ocupando, cada uno, el lugar que poseían antes de derrumbarse el techo, pero lo que sí se puede conocer es que todos ellos se hallaban presentes en un momento determinado, aquél previo al incendio y derrumbe. En este sentido, cobra relevancia la separación de los objetos aplastados por el techo de aquéllos que se hallan incluidos en [12].

A la unidad [12] se la definió como un piso. Los pisos de tierra, aun cuando presenten un alto grado de consolidación, no son unidades totalmente impermeables, pudiendo contener inclusiones producto de acciones tales como barrido, pisoteo, extracción e inclusión de material (D'Amore 2007; Haber 1996). En ese sentido, las inclusiones de [12] representarían una parte de todas las acciones llevadas a cabo en el lugar. De modo que si se asignaba como inclusión de [12] tanto a los objetos que apoyaban en él -antes de derrumbarse el techo-, como a aquéllos que estaban insertos en sus sedimentos, se hubiera perdido la posibilidad de vincular los primeros con las otras unidades estratigráficas que apoyaban o cortaban a [12]. Tanto estas unidades como los objetos apoyados en [12] formaban parte y estructuraban la geografía de la casa en un día específico determinado, como aquél previo al incendio y caída del techo de la habitación. Esto no quiere 


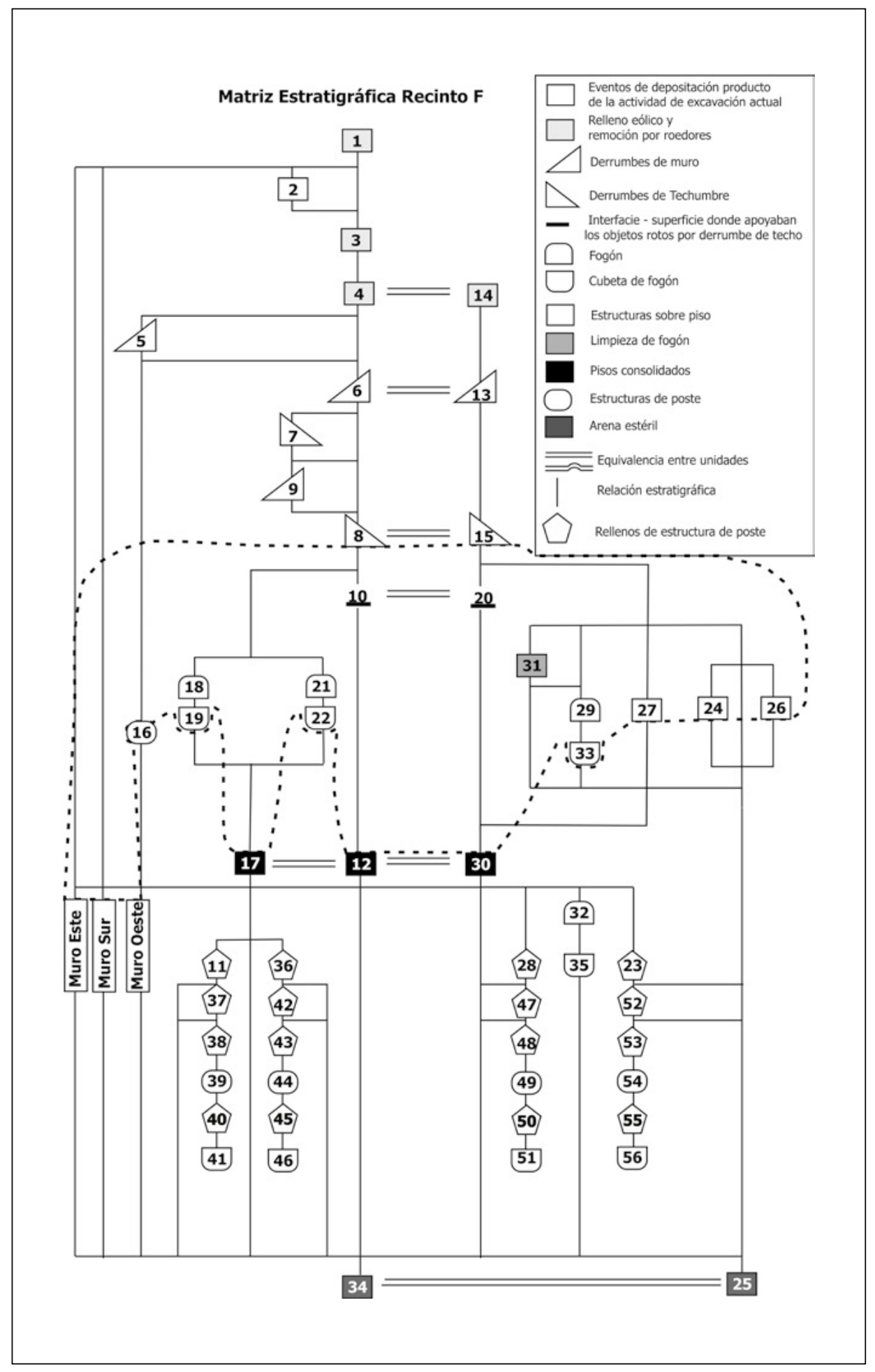

Figura 8. Matriz estratigráfica reinterpretada. Con línea de puntos se indica la interfacie de período. 
decir que las inclusiones del piso [12] no formasen parte de esta geografía, pero, a diferencia de [10], nos remiten a un tiempo más prolongado, en el que se condensa parte de la historia ocurrida en el lugar. Si comparamos el número de inclusiones registradas en [12], con el número de inclusiones registradas en [10], observamos una gran discordancia entre la cantidad y variedad de objetos utilizados diariamente, y lo que quedó de ellos como inclusión del piso [12] (del total de inclusiones registradas en la excavación, el $65.61 \%$ corresponde a [10] y solo el $17 \%$ a [12]). Este hecho nos informa de una práctica de limpieza continua del piso de la habitación y de la extracción de las cosas rotas fuera de la misma. Las prácticas de limpieza aparecen así como fuertes demarcadores de esa geografía cotidiana, y a su vez, provocan que los objetos que apoyaban en la interfacie de [12], aplastados por el techo, y los fragmentos incluidos en [12], es decir, aquéllos que las limpiezas del piso no lograron barrer, se vinculen en otro plano. Los últimos son representantes de objetos que estructuraron otras geografías cotidianas sucedidas en la habitación, y que, al incorporarse a esta geografía -[1o]- como inclusión del piso, expresan un proceso de más larga duración; esto nos lleva a analizar qué sucede con esos objetos que extrajo la limpieza.

Tirando la basura: reencontrando el lugar de la materia. La identificación de recurrentes limpiezas de los pisos, y la extracción de estos restos fuera del recinto, nos permiten vincular esta habitación y las acciones de limpieza realizadas en ella, con el montículo que forma parte de Piedras Blancas. El análisis de la estratigrafía del mismo a continuación, permitirá reforzar la idea del origen doméstico de esta estructura.

Ella alcanza una altura de $2 \mathrm{~m}$, es de forma ovalada y tiene un largo de aproximadamente 25x15 $\mathrm{m}$ de ancho. La Figura 9 muestra el dibujo del perfil sur de una trinchera realizada al montículo en sentido este-oeste (TM en Figura 1). En este perfil se puede observar la superposición estratigráfica de diferentes estratos, al menos 22 unidades estratigráficas. Esta estructura no fue excavada siguiendo los lineamientos de Harris, por lo que la cantidad de unidades posibles de registrar, es ampliamente mayor a la matriz estratigráfica que permite reconstruir la sección de dicha trinchera. ${ }^{12}$ A pesar de esto, la matriz

12 La matriz se creó en base al dibujo y descripción de la sección norte de la trinchera del montículo. Fue retomado y modificado reconstruida de la sección nos permite observar el proceso de formación del montículo.

La disposición de dichas unidades presenta un buzamiento - dirección de pendiente- hacia el este, lo que nos está indicando el sentido de la pendiente de la superficie donde se depositó cada una de ellas. Las 22 unidades son indicativas de una variedad de acciones que le fueron dando a este lugar la forma de una estructura monticular. Algunas de estas unidades poseen mayor volumen de sedimento que otras, las unidades [2], [4], [19], [18], [15], [20] y [14], mientras que los depósitos de ceniza y carbón [21], [5], [6], [7], [8], [9], [3], [13] y [16], y el sedimento compacto [11] poseen un volumen de sedimento menor. En la matriz estratigráfica construida de esta sección, se pueden apreciar las relaciones estratigráficas entre las distintas unidades. Estas relaciones, al indicarnos una cronología relativa de depositación de las mismas, nos permiten observar la recurrencia de algunas acciones en la formación del montículo, tales como la depositación de sedimento ceniciento y carbonoso, o la depositación de sedimento con fragmentos de muro de tapia derrumbado o quizás producto de remodelaciones de los espacios interiores. Estos depósitos pueden vincularse con lo registrado en la habitación, como por ejemplo, la unidad estratigráfica [31], que conforma los restos de una de las limpiezas del fogón [29], o los fragmentos de muro de tapia derrumbados hallados mientras se extraía el derrumbe del techo [8], semejantes a los hallados en distintas unidades estratigráficas del montículo.

Las inclusiones que contienen los diferentes estratos que componen el montículo pueden ser caracterizadas como representativas de gran parte de las cosas usadas en el sitio: restos de animales consumidos -en su mayoría de camélidos-, fragmentos de huesos humanos -que suelen aparecer como inclusión de los pisos-, pigmentos, semillas, instrumentos líticos -específicamente de cuarzo-, fragmentos de vasijas cerámica, fragmentos de pipas, de platos y demás objetos elaborados en cerámica, fragmentos de objetos de metal, e incluso pequeños lingotes de cobre arsenical, etcétera.

de Cruz (2005). Dicha excavación fue realizada en el año 1999 y estuvo dirigida por Pablo Cruz y Bernarda Marconetto. 


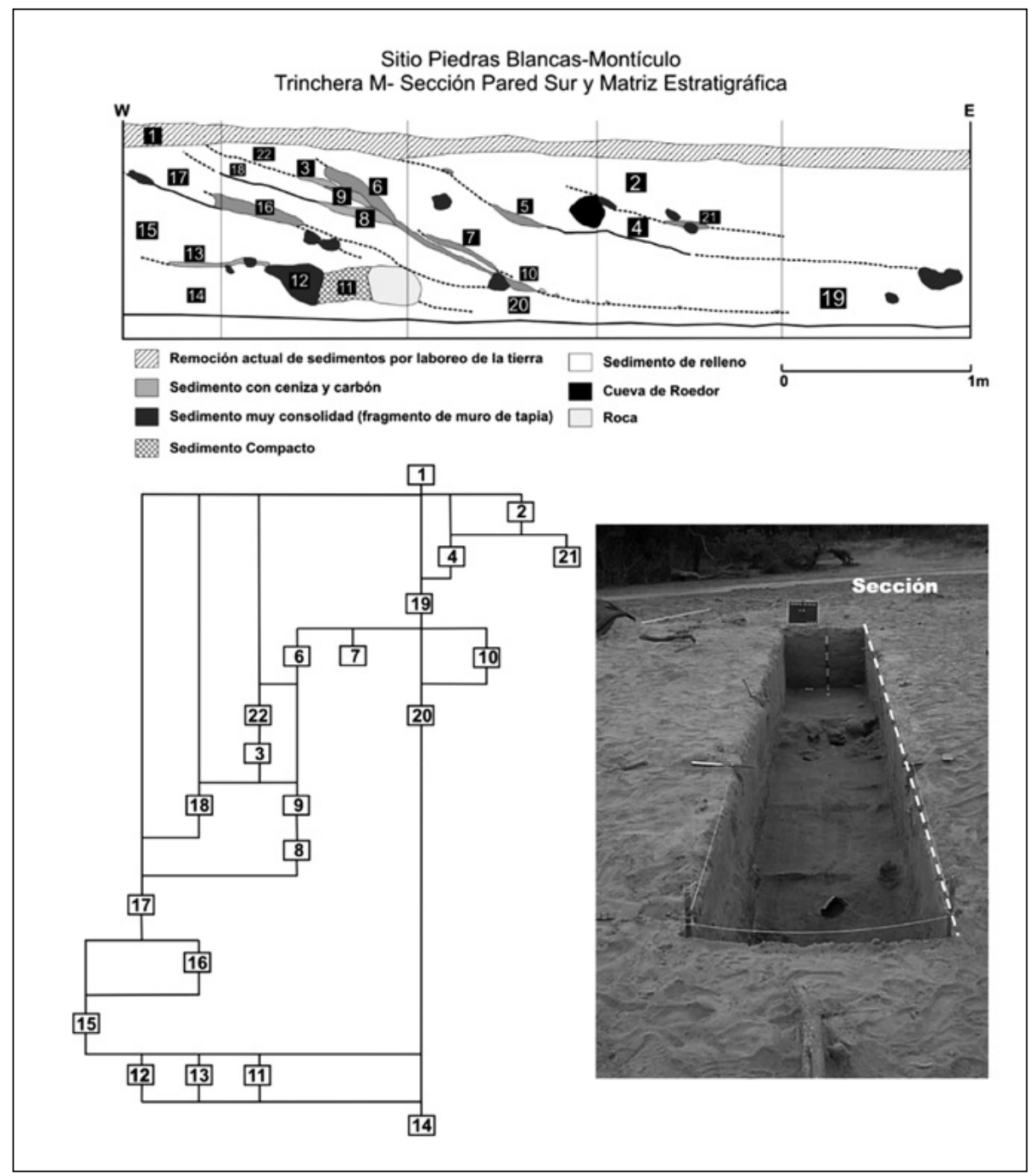

Figura 9. Trinchera M en montículo de sitio Piedras Blancas:

Dibujo de corte del perfil sur, Matriz de Harris de la estratigrafía y vista general de la excavación.

La mayor cantidad de materiales que contiene el montículo se compone de fragmentos cerámicos y restos óseos. En el caso de los restos óseos animales, Dantas (2013) señaló que tanto en las habitaciones como en el montículo, no existen diferencias a nivel de especies representadas. A nivel de todo el sitio Piedras Blancas se da el predominio notorio de Artiodactyla, ya que sumado con los elementos de camélidos y cérvidos alcanzan valores cercanos o superiores al $70 \%$ del conjunto identificado (Dantas 2013: 6). En relación a la distribución de partes anatómicas y de edad de los individuos de las especies más representadas como el camélido, se encuentran proporciones semejantes en los recintos y en el montículo. Principalmente se observa la presencia de la carcasa completa y un predominio de individuos adultos (Dantas 2013: 10). Otro punto de comparación es la fragmentación del conjunto, que es idéntica en los recintos y en los estratos provenientes del montículo -un $89 \%$ de representación de fragmentos de entre $0,5 \mathrm{~cm}$ y $10 \mathrm{~cm}-$ (Dantas 2013: 14).

Otro hecho que favorece esta interpretación es el análisis del material cerámico. En mi tesis doctoral (Gastaldi 2010) he establecido las biografías culturales y trayectorias de vida de las vasijas en el valle de Ambato. En estas historias, las diferentes formas y clases 
de vasijas (las grandes vasijas tricolor, las vasijas más pequeñas y pucos negros gris grabados, como también las ollas más toscas usadas para cocinar) funcionan y se mueven como si fueran familias de vasijas, que según las actividades en las que participan se juntas y se disgregan. La mayoría de ellas tienen largos recorridos; hemos podido determinar al menos tres situaciones en las que pueden participar a lo largo de sus vidas: fermentación de bebidas, almacenaje de productos vegetales como chañar -Geoffroea decorticans-, carnes, acumulación de pigmentos. Estas actividades son realizadas en muchos de los casos de manera secuencial. Las huellas que dejan pueden reconocerse en sus cuerpos: estrías y desgastes son especies de marcas nemónicas de sus historias. Al final de la vida útil de estas vasijas, cuando se rompen o se dejan de usar, parte de sus fragmentos se muelen y se incorporan como antiplástico a las otras vasijas que se fabrican en las mismas casas; una parte de ellas se reciclan para sostén de otras vasijas o fabricación de platos, mientras gran parte de los fragmentos se arrojan a los montículos basureros cercanos a las viviendas. Se observa en el caso de la cerámica una alta referencialidad en los conjuntos del montículo y las habitaciones.

También los objetos de metal permiten señalar la procedencia doméstica de la mayoría de los restos del montículo. Espósito (2009) describe cómo en el recinto H de Piedras Blancas (Figura 1), que se describe como taller artesanal, y en otros sitios de vivienda como Martínez 2 y Martínez 4, aparecen herramientas de metal, como cinceles de cobre arsenical asociado a la producción de vasijas cerámicas, que los encuentra también en los montículos basureros.

Si sumamos a lo anterior los fechados obtenidos, se observa que el tiempo de vida de uso del montículo coincide con el de las habitaciones del sitio. Por otra parte muestra un proceso de larga conformación de esta estructura monticular. Se poseen dos fechados provenientes del montículo, el más antiguo $1340 \pm_{40} \mathrm{AP}$ y el más tardío $1040 \pm 50 \mathrm{AP}$; en años radiocarbónicos estas dataciones indican alrededor de 300 años de diferencia. Si se los compara con las fechas que provienen de dos habitaciones del sitio, en que la más antigua es de $1370 \pm 70 \mathrm{AP}-$ Piedras Blancas, Recinto $\mathrm{C}-$ y la más tardía es de $920 \pm 70 \mathrm{AP}-$ Piedras Blancas, Recinto F-, se observa la contemporaneidad del uso del montículo y de las habitaciones. ${ }^{13}$

Teniendo en consideración todo lo anterior se puede señalar que al montículo, entonces, se le fueron depositando gran parte de las cosas y objetos que eran extraídos de las habitaciones por medio de las prácticas de limpieza. De esta forma, las actividades de limpieza de los pisos se conformaron como prácticas que mediaron entre los objetos que se hallaban estructurando la geografía de la habitación en un día determinado, y aquellos objetos que como desechos quedaron, en parte, incorporados como inclusión de la unidad estratigráfica 12 -representantes de otras geografías cotidianas en el recinto $\mathrm{F}-\mathrm{y}$ en parte también fueron depositados al montículo. Estos últimos desechos comenzaron así a participar de una temporalidad mucho más larga, la de formación del montículo, con un tiempo de al menos 300 años. ${ }^{14}$

Si desde las habitaciones la coreografía de la limpieza extrae material hacia afuera, no solo de los recintos sino de la casa, cuando nos paramos sobre el montículo, se observa un movimiento inverso. Estas estructuras ejercen una fuerza centrípeta que atrae dichos materiales que quedaron, como señala Mary Douglas, "fuera de lugar", otorgándole un espacio bien delimitado en su seno. Si las prácticas de limpieza de la casa se convierten en acciones negativas, es decir que al limpiar todo el tiempo invisibilizan las acciones cotidianas llevadas a cabo en dichos lugares, en el montículo esas actividades y sus restos se transforman en acciones positivas; se transforman en alimento de esas estructuras, al acumularse y sedimentarse.

13 Ver Marconetto et al. (2014) para una discusión de los fechados del sitio y de todo el valle.

14 Existen otros sitios que presentan montículos asociados que arrojaron fechas que marcan también una prolongada formación de estas estructuras. El caso del sitio Iglesia de los Indios posee fechados que van del $1800 \pm 80 \mathrm{AP}-\mathrm{LR}$ muestra $6-$ al $840 \pm 55$ -LR muestra 8-, es decir que en años radiocarbónicos la ocupación del sitio es de uno 960 años de duración, lapso en el que el montículo se fue formando. Otro caso es el del sitio Martínez 2, donde el fechado más temprano que posee es de $1690 \pm 80-\mathrm{M}_{2}$ sec W(1) - y el más tardío 990 $\pm 70 \mathrm{AP}-\mathrm{M} 2$ sec W(2)-, es decir unos 600 años. Los otros dos montículos que poseen fechados son Martínez 3 con una fecha radiocarbónica de $1700 \pm 60$ AP y Martínez $11770 \pm 90$ AP, aunque al poseer solo un fechado no podemos saber hasta cuándo se estuvieron formando. 
En primer lugar, la construcción del montículo de Piedras Blancas (extensible a otros montículos hallados y excavados en el valle) como estructura sobreelevada, no fue ejecutada de una sola vez, requirió de intervenciones periódicas y continuas, durante las cuales y por largo tiempo le fueron siendo incorporados los diversos elementos que lo constituyeron como tal. En segundo lugar, los materiales que lo iban transformando en montículo, son representativos de las diferentes actividades realizadas en el sitio durante un lapso temporal muy amplio, vinculando este espacio a varias generaciones de personas que habitaron la casa. En función de estas características, podemos plantear que el montículo es un lugar donde se intersectan y conjugan una multiplicidad de significados diferentes, que nos refieren a los circuitos cotidianos donde los diversos objetos depositados allí y las personas que los depositaron estaban insertos. Además, es donde estos circuitos cotidianos pasarían a formar parte indisoluble de una temporalidad muy larga vinculada a la historia de formación, de "sedimentación", de esta estructura. En el caso del montículo, este proceso de sedimentación realiza otro proceso, el de "monumentalización". La sedimentación -y no solo la visibilidad y durabilidad-, es lo que produce que el montículo se transforme en monumento. El montículo como monumento, imprime a las sendas biográficas de sujetos y objetos depositados en él, una temporalidad no histórica y descontextualizada. Continuamente, las prácticas de limpieza descriptas no solo actualizan las interfacies donde ocurre la vida social, sino que están mediando la articulación entre contingencia y estructura, en tanto es a través de ellas que los objetos, al ser incorporados a los montículos, pasan como sedimento a la larga duración. ${ }^{15}$ Se podría decir que son la expresión de una memoria que, dada su dilatada temporalidad, es en cierta forma inmemorial.

\section{Topografías emergentes: el monumento, la casa y la comunidad}

Al analizar el lugar donde están emplazados los montículos basureros en los distintos sitios del valle, se observa que dicho espacio comprende un área en cierta forma exterior a las casas; un espacio que no posee una demarca-

15 Larga duración en el sentido de Braudel (1968: 60-106). ción, lo que se podría decir el "más allá" de la vivienda, por lo menos materialmente marcada. Pero en cambio, todos los sitios de vivienda sin importar el tamaño, poseen muros y vanos que limitan el acceso a los patios y habitaciones. En el caso del sitio Piedras Blancas, el montículo está por fuera del muro de cuarzo que da acceso al sitio, justo enfrente de la entrada al mismo (Figura 1). Puede decirse lo mismo para los montículos basureros de sitios como Martínez I (Assandri 1991) y Martínez 3 (Ávila y Herrero 1991), ubicados más al norte del sitio Piedras Blancas. En el caso del sitio La Rinconada (Figura 10), que posee una plataforma que corona un espacio central a manera de plaza (desde el cual se puede acceder traspasando ciertos vanos y puertas a patios, galerías y recintos techados), no posee muros que restrinjan su acceso, su lado oeste está totalmente abierto, es permeable e invita a la visita.

El área más externa de las viviendas, donde se encuentran los montículos, es una suerte de región liminal entre el espacio que es compartido por los que habitan las casas y aquel otro compartido por éstos con los "vecinos". Dicha región refiere a relaciones y colectividades mayores, de las que habitan las casas, que median la articulación de estos grupos a un paisaje mayor. El lugar liminal, más colectivo o comunitario donde están emplazadas estas estructuras monticulares, es reforzado si tenemos en cuenta lo señalado por Assandri (2010), quien plantea que existe una alta intervisibilidad (de $80 \%$ a $90 \%$ ) entre todos los sitios de vivienda. En este sentido, existe la construcción de un espacio de encuentro común, al menos, que invita a verse. Ese espacio intervisible articula un sentido de inmediatez social, de posibilidades de encuentros entre los habitantes de las distintas casas, necesario para la construcción de relaciones más colectivas, supradomésticas y comunitarias. En este sentido, el montículo en ese espacio ocupa un lugar ambivalente. Como representante de prácticas más restringidas y habitante de espacios más colectivos, es una especie de 'entre-medio' entre la casa y la comunidad, no se encuentra completamente ni en uno ni en otro lugar, está en ambos. Es en ese lugar de ambivalencia, en ese entre-medio, donde podemos apreciar el diálogo mediante el cual los grupos de pertenencia a nivel doméstico, se pensaron y representaron a sí mismos en relación a los otros grupos habitantes del valle. Ese diálogo fue práctico y material; el simple hecho de barrer y tirar en el montículo las cosas usadas en la casa, 


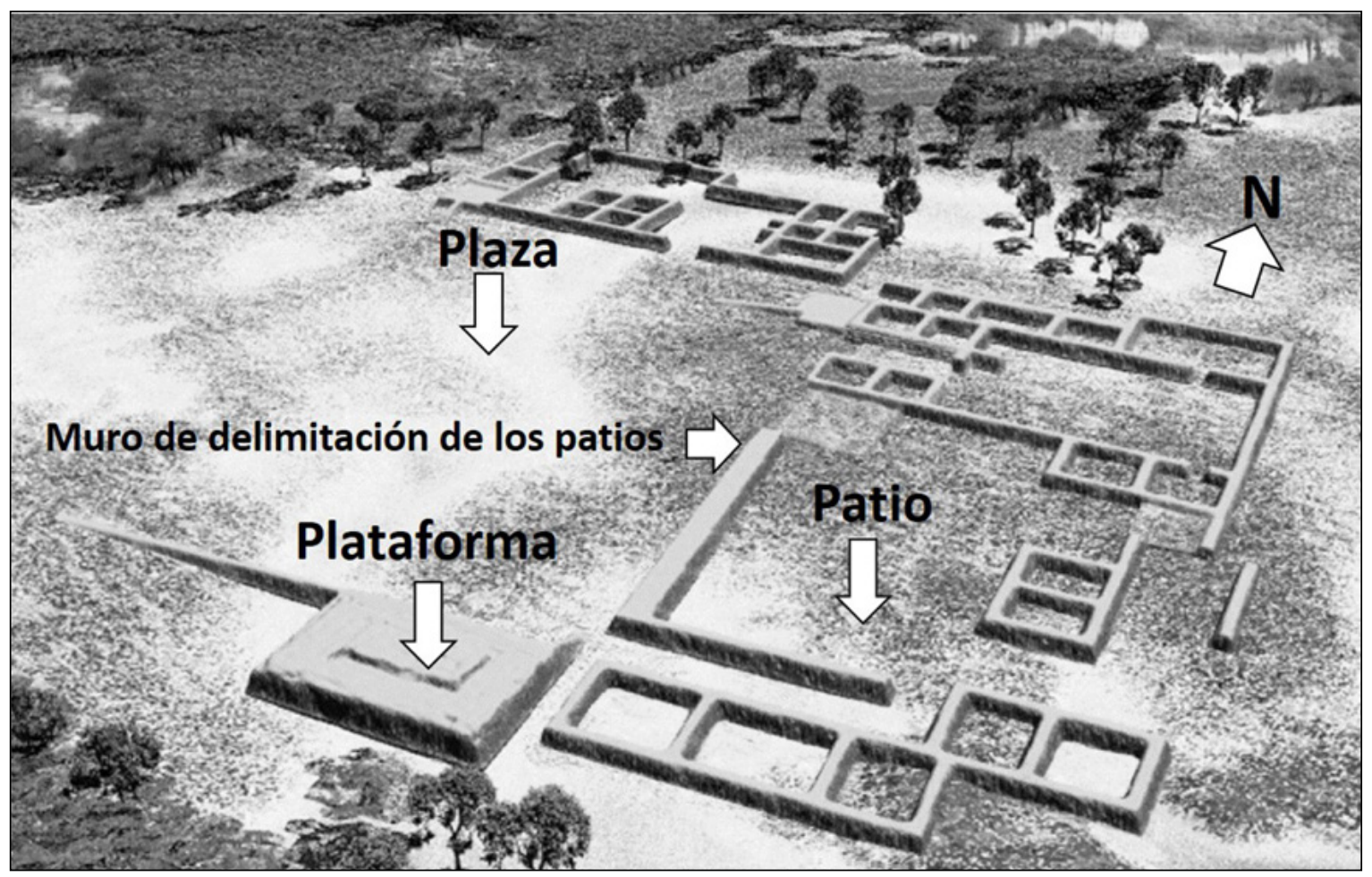

Figura 10. Recreación en perspectiva ortogonal del sitio La Rinconada o Iglesia de los Indios. Modificado de Gordillo (2009).

objetos que poseen historias y biografías particulares que refieren a diversas prácticas, significados y apropiaciones realizadas por los habitantes de ella durante varias generaciones, fue una acción coreográfica positiva de volver a reubicar la materia que quedó fuera de lugar. Esta acción produjo la emergencia de una topografía cultural determinada, aquella mediante la cual el grupo y la casa devinieron monumento, y el monumento, comunidad.

\section{* La tierRa en peligro: topadoras, montícu- LOS, ARQUEOLOGÍA Y COMUNIDAD}

Cuando exponía algunas de las ideas de este trabajo en un congreso, ${ }^{16}$ un colega que estaba escuchando atentamente me interrogó acerca de si mi interpretación de estos montículos no era otra de las capas de senti-

16 Se trata del XIV Congreso Nacional de Arqueología Argentina realizado en San Salvador de Jujuy en el año 2007. En él expusimos una versión preliminar de este trabajo denominada "Fijando sentidos: Montículos y Proceso de Integración Regional: Reflexiones Desde el Valle de Ambato", en el simposio Arqueología de la Materialidad coordinado por Félix Acuto y Andrés Zarankin. dos acumulados sobre estos lugares, que, apropiándose del poder que estas estructuras como monumentos tenían para fijar sentidos a largo plazo, ejercía un acto de violencia epistémica en tanto fijaba la interpretación de la arqueología como disciplina, dejando fuera -invisible- lo que hoy estos lugares significan para aquéllos que viven en el valle. En ese momento intenté dar una respuesta, pero creo que los nervios y la hexis (Bourdieu 1991) disciplinar no me permitieron contestarla adecuadamente; respondí que si bien estos lugares tenían referencias en la actualidad, ya que eran nominados por la comunidad, no lo había considerado en el análisis arqueológico. Como bien interrogaba el colega, las comunidades que habitan el valle sí hacen referencia a estos lugares; si uno visita las casas actuales, muchas de ellas se hallan encima de las casas-montículos arqueológicas, e incluso reutilizan materiales para construirlas: ya sea para realizar los cimientos, levantar corrales, reutilizar antiguos espacios aterrazados como patios o para asentarlas, o también se utilizan pircas que quedaban en pie de la casas de los "indios", como se refieren en el valle a los antiguos pobladores. Es decir, que estas cosas de los 
“indios", no les son indiferentes, sino que se las conoce, se las refiere y se las incorpora a la arquitectura doméstica, a sus propias casas. Esta incorporación de los espacios antiguos de los "indios", no solo se da a nivel arquitectónico o de construcción de las casas, sino que estos lugares monticulares están muy presentes en la narrativa del paisaje local: se los suele designar como "Bordo", "Iglesia" o "Altillo". Los pobladores del valle de Ambato, le llaman "bordo" a toda elevación de factura artificial. Los sitios arqueológicos en general son definidos como "bordos" y "borditos", en tanto que muchas veces los sitios en el valle se presentan en forma de montículos. La forma monticular que adquieren muchos de estos sitios no proviene de arrojar basura, sino del derrumbe de las paredes de adobe y tapia que cuando colapsan forman lomadas suaves. En la narrativa local, "Bordo", "Iglesia" y "Altillo" aparecen en la toponimia utilizada por los habitantes del valle para demarcar los espacios y guiar a la gente cuando pregunta sobre algún lugar o dirección determinada, particularmente en las zonas bajas con mucho monte. Este tipo de toponimia coincide en general con montículos basureros y plataformas: "El Altillo", "Bordos de los Indios", "Bordo del Altor Grande" e "Iglesias de los Indios" son algunos ejemplos -todos ellos poseen montículos basureros, algunos transformados en plataformas-. Es decir, que la visibilidad heredada de su proceso formativo, su monumentalidad, no es ignorada por los pobladores actuales, sino que quizás como antaño, hoy es utilizada de marco de referencia espacial por las personas que habitan alrededor de ellos. Podríamos decir que son hitos, marcas que conforman y denotan el paisaje local. Puesto en estos términos, es esta monumentalidad propia de los montículos la que nos llevó también a prestarles atención.

Este hecho no ocurre solamente en el valle de Ambato. Como se señaló, existen estas clases de estructuras en zonas aledañas. A nivel más regional aparecen en la toponimia y en el repertorio folclórico como "Allpataucas" o "Alpataucas". Estas denominaciones corresponden a una voz quechua en la que allpa-alpa significa tierra y tauca, montón, montón de tierra o tierra amontonada: "En Andalgalá y en Catamarca se llama así al montón de tierra Allpa-Tauca que los antiguos levantaban por todas partes" (Lafone Quevedo 1905). En este sentido, coincide con ciertas categorías utilizadas en Ambato para designar estos lugares como pertenecientes a los "indios", y en el caso de Andalgalá (localidad ubicada del otro lado de la serranía de Ambato-manchado, hacia el oeste) señalados como "de los antiguos". A nivel arqueológico, un hecho interesante que acerca la palabra "Allpatauca" a los montículos basureros, es lo que señala Lafone Quevedo (1905): cuando refiere a estos lugares, escribe que es de donde sale cerámica negra gris grabada de estilo draconiano. Este estilo pasó luego a formar parte de lo que se conoce como cultura de la Aguada de Ambato; justamente el mismo tipo de material que aparece en los montículos del valle. En el Valle de Catamarca-recordemos que geográficamente el valle de Ambato es el sector norte de este otro gran valle- también se les denomina Allpatauca. En él existe un lugar denominado Allpatauca, hoy conocido como San Antonio, en el departamento Fray Mamerto Esquiú. Según los lugareños, el nombre le viene dado por la proximidad de una pequeña loma, "Cara de piedra”, que aún se conserva intacta (Quichua Toponimias 1999). Ardissone (1941) señala, citando al Padre Larrouy, la existencia -a finales del siglo XVI y principios del XVII en San Antonio (Allpatauca) - de viñas, algodonales, acequias y de montículos de tierra denominados Allpatauca por los pobladores indígenas del lugar.

Lo que muestra este pequeño repaso regional e histórico es que las Allpataucas, hasta hoy día con sus nombres genéricos o propios, son incorporadas a las geografías locales; siguen siendo punto de referencia, de orientación, de marcación y de significación. Si uno tiene en cuenta las narrativas locales sobre estos espacios, que en Andalagá los refieren a "los antiguos" y en Ambato a los "indios", la memoria larga en estos lugares parece desenvolverse, en parte, a través de ellos. Como diría Halbwachs (2004), son reconocimientos como parte de las marcas dejadas por los otros: "los antiguos", los "indios". No solo está el uso como referencia de orientación, sino que también se los utiliza de forma comparativa e ilustrativa entre prácticas pasadas y actuales. El montículo denominado "Iglesia de los Indios" es un indicio de ello. Si apeláramos a una metáfora textual, la Iglesia de los Indios podría ser considerada como un texto narrativo, una ilustración sobre la vida de los "indios" que no es tan ajena a aquélla de los ambateños en la actualidad; así como nosotros tenemos iglesias con altares, por ejemplo, los "indios" también tenían las suyas. Hoy, a esos Bordos, Altillos e Iglesias, ya no se les arrojan los residuos provenientes de las casas, pero siguen estando presentes, se los sigue 
invocando como importantes marcadores del paisaje, de orientación y de narración de los tipos de cosas que realizaban los "indios". Nos ocuparemos, para profundizar el lugar que hoy tienen estas estructuras en las narrativas locales, en elaborar aunque sea con ciertos trazos gruesos, el modo en que, en la actualidad, los pobladores en Ambato ${ }^{17}$ piensan el transcurrir del tiempo y la formación del paisaje del valle. Esto nos llevará, por una parte, a reconsiderar la imposibilidad de separar estas estructuras de la producción de la vida hoy en este valle y, por otra, a analizar la violencia epistémica que ejerce la arqueología cuando deja fuera las narrativas locales y los contextos históricos, cosmológicos y políticos específicos donde se inserta. Para realizar esto, se recurrirá a algunas experiencias del autor vividas en el valle y a etnografías realizadas por distintos investigadores en las últimas dos décadas. Si bien estos trabajos son fragmentarios y solo recientemente se emprendieron investigaciones etnográficas más sistemáticas, son suficientes para un primer acercamiento a pensar una teoría local de formación del paisaje del valle.

\section{* La “tierra vuela y no se asienta”: UNA ARQUEOLOGÍA FUERA DE LUGAR}

En las últimas dos décadas, desde que se escribiera el trabajo sobre las casas y los montículos (Haber et al. 1996) en el cual nos apoyamos, y en este mismo instante mientras escribo, la agricultura industrial a gran escala ha crecido exponencialmente en el valle. Si se comparan las imágenes satelitales de inicio de los noventa, con las actuales, en la zona sur del valle -donde se han concentrado mayormente las investigaciones arqueológicas- se observan grandes áreas desmontadas, que contrastan con las pequeñas parcelas observadas en las fotografías aéreas tomadas con anterioridad a la década de 1970 (Assandri y Gastaldi 2014). También se puede observar la reducción de las áreas de cultivo de las comunidades campesinas del valle, que llegaban en la década de los años setenta hasta el Río de Los Puestos en el fondo de valle, y en la actualidad se han reducido a un mínimo, manteniéndose solo en áreas cercanas a los poblados. Este retroceso de áreas de cultivo campesino y el avance

17 Principalmente hacemos referencia a la localidad de Los Castilos, cercana a Piedras Blancas. Es aquí donde se ha concentrado la mayoría de los trabajos etnográficos realizados en el valle que retomamos. de áreas de producción agrícola industrial han sido bien documentados y analizados en la zona central y sur del Valle de Catamarca (Pizarro 2000, 2006).

Justina, ambateña nacida y criada en el valle en la localidad de Los Castillos, nos comentaba hace unos años (2004) acerca de lo difícil de acceder a la "leña" y al "mon$t e$ ". En aquella oportunidad señalaba particularmente que hay alambrados y está muy desmontado, lo cual vuelve muy arduo buscar leña para mantener los fogones, los hornos y las cocinas. Hoy, decía, hay que pagar la leña para traerla en camión o camioneta. Su esposo Agustín, carpintero del poblado de Los Castillos, le dijo en 1999 a Laura Gadban (citada en Marconetto 2008: 192), cuando ella le preguntó sobre la utilización de la madera para su taller y de dónde la extraía: "¿Y qué pasa con los que están tirando [desmonte en estancia La Rinconada cercana a la localidad de Los Castillos] para sembrar pistachos? [a lo que él respondió] Toda esa madera que están sacando, toda la queman..." Más adelante Gadban le preguntó “iSe sigue sacando madera de esta zona? [respuesta] Sí, sí, hay para sacar, pero lo que pasa es que muchas veces falta con qué comprarla y con qué buscar un transporte. Los transportes son los caros aquí. Y ahora hay que traer las cosas de más lejos, más larga distancia, peor todavía. Antes había más cerca, antes habia aquí en la zona pero ya aquí está liquidado". El desmonte, la ampliación de tierras cultivables para la agroindustria, sumado a los alambrados son lo que en los últimos años ha dificultado mantener la relación cercana que las familias poseen con lo que denominan "monte" (Galban 1999 citada en Marconetto 2008; Marconetto 2008; Salguero 2002).

Recientemente Bussi (2015) en un trabajo etnográfico que pretende cartografiar la relación local con el clima, principalmente en relación a la sequía, a la escasez (que señalaba Justina o Agustín años antes), ha vinculado ésta con la idea de "seca". Bussi (2015: 97-100) señala que la "seca" más que ser entendida desde un punto de vista de sequía, propio de las ciencias climatológicas, debemos considerarla como una teoría local sobre las formas de relaciones que se tejen con el ambiente/mundo en un sentido muy amplio. La "seca", para Bussi (2015), no solo está vinculada con escasez de agua y de recursos, sino dirá que es un campo semántico abierto, donde se comparan tiempos y memorias. Con un sentido de marcación de lo que fue antes y de lo que es hoy, en un sentido relativo de cantidad no numérica sino más bien de intensidades, la 
palabra "más" está siempre presente, aunque no solo en un sentido positivo -más agua, más monte, más alimento, etcétera- porque también antes había más hambre, había que realizar más esfuerzo, el sol era más intenso, hacía más frío, las tormentas eran más fuertes. El antes y el hoy no pueden definirse cronológicamente, porque dependen de la persona que comente sobre la "seca"; ya sea que se refieran a 3, 15 o 60 años atrás. Parece vincularse más con narrar percepciones y experiencias vividas por las personas o algún "otro", que con marcar una secuencia cronológica precisa de cuando vino o se instaló la "seca". La "seca", en el sentido dado por la gente de Los Castillos en el valle de Ambato, se vincula a una teoría local que trata sobre el transcurso del tiempo y las experiencias de la vida campesina, familiar y comunitaria. Las intensidades usadas para narrar de manera diferente y comparativa pasado y presente, no están fuera del paisaje circundante sino imbricadas en él, lo forman, y a manera de sedimentos quedan acumuladas en él. Esto se pone de manifiesto en relatos locales sobre la formación de algunos lugares por donde las personas transitan.

Bussi (2015: 103-104) comenta una historia que le narraron sobre un pequeño camino que corre por una especie de cárcava o zanjón llamado "La Peligrosa":

...unos dicen que se formó por las fuertes crecidas y lluvias de los años setenta; otros, que se hizo por la circulación intensa de gente en esos mismos años; y otros, que el nombre se debe a que, antes, las personas escuchaban ruidos extraños ahí, que se relacionaban a la cruz conmemorativa de una muerte que está al final del camino. La cruz fue puesta ahi porque desde ese punto puede verse el lugar en lo alto del valle donde murió el hombre en los años treinta, más o menos. Él estaba pastoreando su majada de cabras cuando de repente se armó una fuerte tormenta, de la que él quiso huir corriendo y buscando refugio. Lo alcanzó un rayo y lo fulminó. Antes de la seca, llovía con empeño, las tormentas se armaban en un abriry cerrar de ojos...

La "seca", son estas historias del lugar que quedan como huellas en el paisaje circundante, no está fuera de la experiencia, se vive en el transcurrir por el peligroso camino, marcado por antiguas inundaciones o fuertes tormentas y muertes trágicas. Se podría decir que ni el camino de La Peligrosa ni el zanjón, estaban de antemano, se hacen en el juego comparativo y presente de la experiencia de la "seca". En este juego de intensidades comparativas, los "bordos de los indios" no quedan fuera. Son parte de estas experiencias narrativas que marcan, producen, forman y crean el paisaje local. Así como la cruz que rememora y exorciza La Peligrosa, los "indios" también tenían su templo para adorar, aquel lugar conocido por todos que es la "Iglesia de los Indios". Dicha comparación como la "seca" no es historia cronológica, sino que es presente, es paisaje, se puede transcurrir por él, orientar al viajero, apreciarlo o compararlo con los templos actuales. Así, pasado y presente se funden en el paisaje, se funden con la tierra y, como diría Ingold (2010), crean y hacen crecer el suelo. En ese sentido, los montículos se engarzan a la experiencia de la "seca" creando el suelo donde vive y se desarrolla la comunidad.

Justina una tarde nos comentaba que a diferencia de antes, hoy "la tierra no se asienta", si bien antes, al igual que ahora se levantaba polvo, las fuertes lluvias y tormentas de antaño lo asentaban de vuelta, lo volvían a su lugar. Hoy parece que la tierra no quiere volver o no puede asentarse, en tanto sigue volando, permaneciendo en el aire. En muchas ocasiones hemos escuchado invocar a Santa Bárbara o como diría Justina, a "Santa Barbarita" que, como señalan Salguero (2002) y Bussi (2015), es en Ambato "la abogada del rayo y las tormentas". Esta experiencia de que la tierra no se asiente como lo hacía antes, que expresa de cierta forma que no está en su lugar, como si fuera una materia que quedó fuera de él -una especie de disolución o volatilización del suelo-, puede ser entendida en parte como una forma narrativa que expresa en términos de la teoría local de formación del paisaje de Ambato, lo que sucede en estos momentos en el valle con la expansión de las zonas de cultivo industrial y el retroceso de las tierras de cultivo campesinas. Quizás la "seca", como lo señala Bussi (2015), como teoría que habla de la formación del paisaje, del suelo y en última instancia del mundo ambateño, narra en su comparación con lo que fue -en un sentido literal más que metafórico-, lo que sucede con el monte y la tierra en el valle hoy, pensemos en lo que refería Agustín respecto de la madera o el monte: "está liquidado".

El retroceso espacial de las tierras campesinas y la concentración de ellas en manos de empresas agroindustriales se produce principalmente a partir de 1994, momento en que la provincia activa una serie de créditos de emprendimientos productivos vinculados al cultivo de no- 
gal, vid, olivo, entre otros (Pizarro 200o). Es en este momento que se producen los mayores desmontes tanto en Ambato como en el resto del valle central y otras zonas de Catamarca. Muchos de los campos son comprados por diferentes empresas para plantar principalmente nogal para la exportación. Por ejemplo, las tierras de las familias Martínez y Saavedra ahora pertenecen a Nueces de Catamarca S.A. En Ambato, en el fondo del valle, solo en el sector sur hemos registrado casi 1300 ha desmontadas para el cultivo industrial (Assandri y Gastaldi 2014). Este tipo de cultivo industrializado para exportación requiere el desmonte de grandes áreas de tierras fértiles, en el caso del valle de Ambato es el fondo de valle. Dadas las características de la agricultura intensiva y las técnicas de desmonte utilizadas, no solo el monte, sino que los sitios arqueológicos, los "bordos" y "borditos" que se hallan en esas áreas son borrados. Los montículos y plataformas son aplanados hasta casi desaparecer. En el caso del montículo de Piedras Blancas, de 2 m de altura, éste pasó a estar hoy totalmente aplanado; la plataforma de la Iglesia de los Indios posee en su cima, como marca de una relación diferente con la tierra por parte del capital empresarial, una fresca huella de tractor indicando, posiblemente, que en ese sector se depositaban fardos para alimentar al ganado vacuno (Figura $2 \mathrm{C}$ ). Desde los inicios de las prospecciones arqueológicas en el valle (1973) hasta la actualidad, hemos detectado la afectación por el desmonte de más 131 sitios, $33 \%$ de los sitios registrados en las áreas de fondo de valle, lugar donde se presentan en general las estructuras monticulares (Assandri y Gastaldi 2014). Algún lector o arqueólogo que conozca la zona dirá que durante años se realizaron excavaciones de huaqueros que afectaron también los sitios. Eso es cierto, muchos de los sitios de fondo de valle están huaqueados, sin embargo estas prácticas no llegaron a borrarlos del paisaje; parte de esta práctica no se vincula solo a la mercantilización de piezas, sino que en algunos casos lo hace con el mismo proceso de apropiación que algunos pobladores realizan de las cosas de los "indios" o de antes.

El incorporar elementos antiguos a la construcción de las casas actuales, no solo puede observarse con respecto a las cosas de los "indios", es una costumbre en el valle. Como bien lo registrara Gadban (1999 citado en Marconetto 2008: 195), los antiguos postes de las casas de los padres y abuelos se incorporan a las casas nuevas, trayéndoselos incluso desde lugares muy lejanos. Agustín, hablando de su taller de carpintería - una construcción de ladrillos de adobe a dos aguas con techo de retama y torta-, que posee aledaño a la cocina de su casa, señala acerca del poste de sostén central de la techumbre:

Éste es Quebracho Colorado [...], éste debe tener casi 2 siglos. Tengo 77 años, yo ya lo conocía, estaba en la casa de un bisabuelo que tenía yo. Eso lo trajeron de hachar leña, después lo tenía en una viga yo, y de ahí lo saqué y lo puse de puntal aquí. Pienso yo que no se va a podrir en la vida: me voy a moriryo, se van a morir mis hijos y él va a quedar, está bajo techo.

Sabemos que la casa a la que se refiere Agustín, perteneciente a sus abuelos, se encuentra en la zona alta de la sierra de la Graciana a bastante distancia de Los Castillos. Es decir, que la incorporación en ella de lo antiguo con valor positivo de perdurabilidad durante varias generaciones, no es ajeno a la tradición local. Algunas de las prácticas que desde la arqueología se definen como huaquerías, se podrían relacionar con esta forma de apropiarse de cosas antiguas, que poseen intensidades positivas en el mundo semántico creado por la "seca", como en este caso la de perdurabilidad. En la definición de Agustín, el poste central de su carpintería se erige como acontecimiento monumental, demarcador del presente y el futuro. Los montículos como monumentos, es decir los "Bordos", el "Altillo" y la "Iglesia", podrían pensarse en esas intensidades, que jalonan el paisaje, lo crean, lo definen, lo fijan.

$\mathrm{Si}$ atendemos a lo que nos deja entrever este esbozo de una teoría local sobre las formas de relación y producción de lugares y tiempos, podríamos decir de formación de la tierra, donde los montículos o bordos de los indios se entrelazan y poseen un lugar preciso en la formación del paisaje de Ambato, podría hoy responderle a aquel colega que mi trabajo expuesto en ese congreso ejerció una violencia disciplinar que se transformó en una navaja muy afilada. Las superficies que nuestro texto creó se escabulleron taimadamente por debajo de la superficie donde se desarrolla la vida hoy. Con un borde bien afilado logró atravesarla y desplazarla a un pasado remoto, separado mil años de la superficie actual. Esta acción estableció una cronopolítica monumental (Gnecco 2006) sobre estos lugares, poniendo el discurso arqueológico como separador de lo que fue y de lo que es. Nuestro texto, tal cual lo señaló el colega, es una capa más de sentido so- 
bre estas estructuras, que como marca disciplinar dejo huellas en la fisonomía del montículo: trincheras, catas, sondeos son marcas de esa violencia. Esta cronopolítica intentó establecer, entre el antes y el ahora, una barrera infranqueable e inalcanzable por la "seca", en tanto el pasado está mil años por debajo del presente y que nada tendría que ver con éste.

La forma específica en que hoy el capital agroindustrial en el valle se vincula con la tierra, sumado a la tecnología que utiliza para producir, no es ajena a la manera en que en muchos casos la arqueología como forma disciplinaria, intenta(tó) desmarcar y remarcar con sus propios símbolos el paisaje local: sometiendo a borradura las relaciones de larga duración que aún mantienen y que perduran en la narración de la "seca". En el caso del capital, la navaja no solo es metafórica y discursiva. Ésta no solo desmonta, arranca, corta el monte, sino que a la vez que retrotrae las tierras campesinas, arrinconándolas alrededor de los pueblos que existen en el valle, pretende borrar de un sopetón esa historia de larga duración entre las casas, los altillos, las iglesias, el paisaje, el monte, la tierra y la comunidad. Una arqueología que reconozca y se haga cargo de que su práctica está inmersa en relaciones de expoliación, desiguales, de continua presión sobre tierras campesinas, con todo el sentido que esto significa en Ambato; una arqueología que pretenda escapar del sesgo de la violencia disciplinar, y en este caso de convertirse en una topadora más, debe reconocer y hacerse cargo de que trata con objetos/sujetos de historias pasadas pero presentes, híbridas, multitemporales, en contextos sociales, políticos y cosmológicos particulares. La palabra tierra aquí, más que referirse a sedimento en sentido geológico, posee un carácter ontológico, en el modo en que los pobladores locales la piensan, la definen y la viven.

\section{* Conclusión}

Empezamos este texto acercándonos, desde una perspectiva arqueológica, a la historia de los montículos del valle de Ambato. En primer lugar, desde esta mirada pudimos -a medida que procedimos con el análisis-, dejar de considerarlos como basureros o simple basura. En segundo lugar, logramos reconstruir el proceso de sedimentación por medio del cual éstos se volvieron monumento de las historias de las casas a las que se asociaban. Luego describimos el tipo de articulación que realizaban entre los grupos domésticos habitantes de las viviendas y colectividades mayores que los trascendían. En la historia que narramos, observamos cómo los montículos se convirtieron en verdaderos monumentos, reconocibles hasta hoy día en el paisaje del valle. En una segunda parte del artículo, tensionamos esta perspectiva con la visión local que los pobladores del valle poseen sobre los montículos. Para ellos ya ocupaban un lugar determinado en la formación del paisaje del valle, que se engarzaba a la idea de la "seca". Los montículos aquí se escapan de lo arqueológico y se entretejen a otros elementos del paisaje que poseen intensidades de perdurabilidad positivas, como los postes de las casas de los abuelos. Con esta recontextualización de nuestra intepretación, dejamos al descubierto los límites y la violencia epistémica que ejercemos, y con mayor intensidad en contextos de presión sobre las tierras campesinas, cuando nos erigimos como la única voz autorizada para narrar el pasado.

Si la arqueología pretende escaparse de la cadena de flujo en la cual termina siendo materia prima de la producción, de la tecnología de arrasamiento que usan las empresas agroindustriales para hacer producir la tierra donde el capital pueda fructificar libremente, y junto con los ambateños, contribuir a que la tierra no se vuele, a que la tierra vuelva a encontrar su lugar, para que como dicen en Ambato "se asiente", no tiene muchos senderos para recorrer: traer las cosas enviadas al pasado poniéndolas en el presente, dialogar con las formas de relaciones locales en las que los objetos que estudiamos están inmersos, es la única posición en la cual los arqueólogos podemos encontrar un lugar donde no seamos solo una pala más de la topadora del avance colonial sobre tierras campesinas. Con este trabajo se espera haber comenzado a transitar un sendero que nos permita conservar la esperanza de que nuestras narrativas sobre esos espacios hayan transcurrido desde ser materia fuera de lugar, a ser parte de las topografías emergentes en las cuales los montículos, los "bordos", la "seca" en el valle de Ambato se hallan con el sendero de la comunidad.

Agradecimientos En primer lugar agradezco a Andrés Laguens, quien fue director de mi tesis doctoral, en la cual se basa parte del artículo. A Bernarda Marconetto, su lectura atenta y crítica del manuscrito. A Mariano Bussi, sus charlas sobre la seca en Ambato. Agradezco además, a Justina Seco, a su hija "la Negra" y a su nieto 
Alejandro por recibirme siempre con el corazón abierto en su casa de Los Castillos en el valle de Ambato. Asimismo quiero agradecer a mis compañeros de laboratorio con quienes compartí las campañas y el día a día de la investigación arqueológica: Susana Assandri, Francisco Pazzarelli, Henry Lindskoug, Mabel García, Verónica
Morse, Germán Figueroa y Mariana Dantas. Claudia Amuhedo me facilitó bibliografía muy útil para mejorar el presente artículo. Un especial agradecimiento a mi compañera de vida, Irene, por su paciencia en la corrección gramatical de este trabajo y por su ayuda en la traducción del resumen.

\section{$\bullet$ Referencias citadas}

ARDISSONE, R. 1941. La Instalación Humana en el Valle de Catamarca. Estudio Antropogeográfico. Facultad de Humanidades y Ciencias de la Educación. Universidad Nacional de La Plata, La Plata.

ASSANDRI, S. B. 1991. Primeros resultados de la excavación en el sitio Martínez I (Catamarca, Argentina). Publicaciones del CIFFy $H$ 46: $53-85$.

ASSANDRI, S. B. 2007. Procesos de complejización social y organización espacial en el Valle de Ambato, Catamarca. Tesis de Maestría en Arqueología Social. Publicaciones Tesis. Formato Digital. Universidad Internacional de Andalucía, España.

ASSANDRI, S. B. 2010. Espacio de asentamiento y campos visuales en la arqueología del Valle de Ambato, Catamarca, Argentina. Revista del Museo de Antropología, vol. 3: 61-76.

ASSANDRI, S. y M. R. GASTALDI. 2014. Atlas Gis: Proyecto Arqueológico Ambato. Informe técnico digital. IDACOR-CONICET.

ÁVILA, A. y R. HERRERO. 1991. Secuencia estratigráfica del sitio arqueológico Martínez 3, Departamento de Ambato, Catamarca. Publicaciones del CIFFYH 46: 17-52.

AYALA, P. 2007. Memorialización estatal del pasado indígena y las políticas de la memoria atacameña. Revista de Antropología 19: $37-62$.

BERBERIAN, E. E. y A. E. NIELSEN. 1988. Sistemas de asentamiento prehispánicos en la etapa formativa del Valle de Tafí (Pcia. de Tucumán-República Argentina). En Sistemas de Asentamiento Prehispánicos en el Valle de Tafi, E. E. Berberián (Ed.), pp. 21-53. Editorial Comechingonia, Córdoba.

BOURDIEU, P. 1991. El sentido práctico. Taurus, Madrid.

BRAUDEL, F. 1968. La historia y las ciencias sociales. Siglo XXI, Madrid.

BUSSI, M. 2015. Decompostura o muerte. Una aproximación etnográfica a las relaciones entre humanos y fenómenos meteorológicos en Los Castillos (Catamarca). Trabajo Final para optar al grado de Licenciado en Antropología.
CARANDINI, A. 1997. Historias en la tierra. Manual de excavación arqueológica. Traducido por X. Dupré Raventós. Editorial Crítica (Grijalbo Mondadori), Barcelona.

CRIADO BOADO, F. 1989. We, the Post-megalithic People. En The Meanings of Things. Material Culture and Symbolic Expression, I. Hodder (Ed.), pp. 79-89. Harper Collins Academic, London.

CRIADO BOADO, F. 1991. Tiempos prehistóricos y espacios modernos. Historia y Crítica: 85-108.

CRESPO, C. 2006. Entre el "deber" y el "derecho": patrimonio arqueológico y obligaciones sociales en Patagonia Argentina. Intersecciones en Antropología 7: 63-75.

CRUZ, P. 2005. Archéologie de la mort dans la Vallée d'Ambato. Homme et milieu dans le Bassin de Los Puestos (Catamarca-Argentine) durant la Période d'Intégration Régionale (IVe-Xe siècles après J-C.). Tesis Doctoral inédita. La Sorbonne, France.

CURTONI, R. y M. G. CHAPARRO. 2008. El re-entierro del cacique José Gregorio Yancamil. Patrimonio, política y memoria de piedra en la pampa Argentina. Revista Chilena de Antropología 19: $19-36$.

D'AMORE, L. 2007. Narrar las prácticas del pasado: el potencial de la estratigrafía arqueológica como representativa de prácticas sociales. Intersecciones en Antropología 8: 101-119. $\mathrm{UNCPB}$, Argentina.

DANTAS, M. 2013. Registro faunístico y diferenciación social: el caso de Piedras Blancas, Valle de Ambato, Catamarca (siglos VIXI d.C.). En De la Puna a las Sierras. Avances y Perspectivas en Zooarqueología Andina, A. Izeta y G. L. Mengoni Goñalons (Eds.), pp. 5-22. BAR, London.

DOUGLAS, M. 1973. Pureza y peligro: un análisis de los conocimientos de contaminación y tabú. Siglo XXI, Madrid.

ENDERE, M. 2011. Cacique Inakayal. La primera restitución de restos humanos ordenada por ley. Corpus. Archivos virtuales de la alteridad americana, vol. 1, núm. 1: 1-7 URL: http://ppct.caicyt.gov. ar/index.php/corpus/article/view/320/102 
ENDERE, M. y R. CURTONI. 2006. Entre lonkos y “ólogos”. La participación de la comunidad indígena Rankülche argentina en la investigación arqueológica. Arqueología suramericana 2(1): 7292.

ESPÓSITO, G. 2009. De clasificaciones y categorizaciones: Los objetos de metal del Valle de Ambato, Catamarca, 600-1200 d.C. BAR Internacional Series, Oxford.

FABRA, M. 2008. Producción tecnológica y cambio social en sociedades agrícolas prehispánicas (Valle de Ambato, Catamarca). BAR International Series, Oxford.

FUNARI, P. y A. ZARANKIN. 2006. Arqueología de la Represión y la Resistencia en América Latina (1960-1980). Encuentro Grupo editor y Brujas, Córdoba.

GALVAN, J. V., S. R. BERTOLINO, A. LAGUENS, J. RIVEROS and G. CATELLANO. 2010. X-ray and Scanning Electron Microscopy archaeometric studies of pigments and ceramic surface paintings from the Aguada Culture, Argentina. Microchemical Journal 96: 259-268.

GASTALDI, M. R. 2007. Tecnología y Sociedad: Biografia e Historia Social de Las Palas del Oasis de Tebenquiche Chico. BAR Internacional Serie, Oxford, Inglaterra.

GASTALDI, M. R. 2010. Cultura Material, Construcción de Identidades y Transformaciones Sociales en el Valle de Ambato. Primer Milenio d.C. Tesis doctoral, Facultad de Ciencias Naturales y Museo, Universidad Nacional de La Plata.

GASTALDI, M. R. 2012. El lugar de los objetos en la teoría estratigráfica de Edward C. Harris: reflexiones desde una habitación del Valle de Ambato, Argentina. Intersecciones en Antropología 13 (1): 89-101.

GASTALDI, M. R. 2013. Instrucciones para Fabricar un Cuerpo: Identidades y Devenir en el Valle de Ambato (NO Argentino). Siglos V a XI d.C.Actas Digitales. X RAM (Reunión de Antropología del Mercosur) organizada por la FFyH-UNC, Córdoba.

GEERTZ, C. 1992. La interpretación de las culturas. Gedisa, Barcelona.

GNECCO, C. 2006. Territorio y alteridad étnica: fragmentos para una genealogía. En (Des) territorialidades y (NO) lugares: procesos de configuración y transformación social del espacio, D. H. Gómez y Piazzini Suárez (Eds.), pp. 221-246. La Carreta Editores, Medellín.

GNECCO, C. y P. AYALA. 2010. ¿Qué hacer? Elementos para una discusión. En: Pueblos indigenas y arqueología en América Latina, C. Gnecco y P. Ayala (Eds.), pp. 23-48. Universidad de los Andes, Colombia.
GONZÁLEZ, A. R. 1977. Arte precolombino de la Argentina. Introducción a su historia cultural. Filmediciones Valero, Buenos Aires.

GORDILLO, I. 2009. El Sitio ceremonial de la Rinconada: Organización socio espacial y religión en el Valle de Ambato (Catamarca, Argentina). BAR Internacional Series, Oxford.

GORDILLO, T. y A. SOLARI. 2009. Prácticas mortuorias entre las poblaciones del Valle de Ambato (Catamarca, Argentina). En Revista Española de Antropología Americana 39(1):31-51.

HABER, A. F. 1996. La estrategia y la construcción del tiempo en arqueología. Comentarios sobre la teoría de Harris. Shincal 5: 27-34.

HABER, A. F. 2006. Una arqueología de los oasis puneños. Domesticidad, interacción e identidad en Antofalla, primer y segundo milenios d.C. Universidad del Cauca y Jorge Sarmiento, Córdoba.

HABER, A. F. 2011a. El lado oscuro del patrimonio. Jangwa Pana. Revista del Programa de Antropología 10(1): 13-25.

HABER, A. F. 2011b. La casa, las cosas y los dioses. Arquitectura doméstica, paisaje campesino y teoría local. Encuentro Grupo editor, Córdoba.

HABER, A. F. y M. R. GASTALDI. 2006. Vida con palas. Antípodas. Revista de antropología y arqueología 2: 275-302.

HABER A., A. LAGUENS y M. BONNIN. 1996-97. Montículo y casa. Elementos retóricos en la cultural material Ambato. Shincal. Revista de la Escuela de Arqueología 6: 59-64.

HALBWACHS, M. 2004. La memoria colectiva. Prensas Universitarias de Zaragoza.

HARRIS, E. C. 1991 [1989]. Principios de estratigrafía arqueológica, E. Junyent (Trad.). Editorial Crítica, Barcelona.

HERRERO, R. y A. ÁVILA. 1991. Excavaciones en la unidad residencia ScatAmb 004 (Martínez 4) del Período de Integración Regional. Publicaciones del CIFFYH 46: 111-130.

HODDER, I. 1988 [1986]. Interpretación en arqueología. Corrientes actuales. Traducción de M. E. Aubet. Crítica, Barcelona.

HODDER, I. 1997. Always momentary, fluid and flexible: towards a reflexive excavation methodology. Antiquity 71(273): 691-700.

INGOLD, T. 1993. The Temporality of the Landscape. World Archaeology 25: 152-174.

INGOLD, T. 2010. Footprints through the weather-world: walking, breathing, knowing. Journal of the Royal Anthropological Institute (N.S.): 121-139. 
INGOLD, T. 2013. Making: anthropology, archaeology, art and architecture. Routledge, London, New York.

JOFRÉ, K. 2010. El regreso de los muertos y las promesas del oro. Patrimonio arqueológico en conflicto. Encuentro Grupo Editor, Facultad de Filosofía y Humanidades UNC, Editorial Brujas, Córdoba.

JOFRÉ, I. y R. MOLINA OTÁROLA. 2009. Territorios indígenas, patrimonio y arqueología: un debate necesario. Jangwa Pana, Revista de Antropología 8: 165-178. Santa Marta, Colombia.

JUEZ, S. 1991. Unidad arqueológica Rodeo Grande, Valle de Ambato: excavaciones en el sitio Martínez 2. Publicaciones del CIFFy $H$ 46: 87-110.

LAFONE QUEVEDO, S. A. 1905. Viaje Arqueológico en la región de Andalgalá 1902-1903. Revista del Museo de La Plata XII: 3-38. La Plata.

LAGUENS, A. G. 2006. Campo y espacio social en el estudio arqueológico de la desigualdad. En Contra la tiranía tipológica en arqueología: Una visión desde Suramérica, C. Gnecco y C. H. Langebaek (Eds.), pp. 99-119. Facultad de Ciencias Sociales, CESO, Universidad de los Andes. Ediciones Uniandes.

LAGUENS, A. G. y M. BONNIN. 1996. Evaluación de series de fechados radiocarbónicos del valle de Ambato, Catamarca. Publicaciones Arqueología 48: 65-101.

LAGUENS, G. y GASTALDI, M. 2008. Registro material, fisicalidad, interioridad, continuidad y discontinuidad: posiciones y oposiciones frente a la naturaleza y las cosas. En Puentes hacia el pasado: reflexiones teóricas en arqueología, D. Jackson, D. Salazar y A. Troncoso (Eds.), pp. 169-189. Sociedad Chilena de Arqueología, Santiago de Chile.

MARCONETO, M. B., M. R. GASTALDI, H. LINDSKOUG, A. LAGUENS. 2014. Merging the matrix: stratigraphy, radiocarbon dates, and fire regimens in the Ambato Valley (Catamarca, NW Argentina). Radiocarbon 56(1): 189-207.

MOORE, H. 1990. Paul Ricoeur: Action, meaning and text. En Reading Material Culture, C. Tiller (Ed.), pp. 85-120. Basil Blackwell, Oxford.

NÚÑEZ REGUEIRO, V. 1998. Arqueología, historia y antropología de los sitios de Alamito. Ediciones Interdea, San Miguel de Tucumán.

OLSEN, B. 2010. In Defense of things. Archaeology and the ontology of objects. Altamira Press, New York.
PÉREZ GOLLÁN, J. A. 1991. La cultura de La Aguada vista desde el Valle de Ambato. Publicaciones del CIFFYH 46: 157-173.

PÉREZ GOLLÁN, J. A. y O. R. HEREDIA. 1975. Investigaciones arqueológicas en el departamento Ambato, Provincia de Catamarca. Relaciones de la Sociedad Antropología IX: 59-68. Buenos Aires.

PÉREZ GOLLÁN, J. A. y O. R. HEREDIA. 1987. Hacia un replanteo de la Cultura de la Aguada. En Cuadernos Instituto Nacional de Antropología 12: 161-178. Buenos Aires.

PIZARRO, C. 2000 . La politica cultural de las movilizaciones campesinas en Catamarca. Las narrativas sobre un conflicto por la tierra en una localidad rural de Catamarca. CENEDIT, Catamarca.

PIZARRO, C. 2006. "Ahora ya somos civilizados": la invisibilidad de la identidad indígena en un área rural del Valle de Catamarca. EDUCC Universidad Católica de Córdoba, Córdoba.

QUESADA, M. N. 2007. Paisajes Agrarios del Área de Antofalla. Procesos de trabajo y escalas sociales de la producción agricola (Primer y segundo milenios d.C.). Tesis de Doctorado inédita, Facultad de Ciencias Naturales y Museo, Universidad Nacional de La Plata, La Plata.

RAFFINO, R. A. 1988. Poblaciones indígenas de la Argentina. Tipográfica Editora Americana, Buenos Aires.

ROMERO, A. G., C. M. SANTORO, D. VALENZUELA, J. R. CHACAMA, E. N. ROSELLO y L. PIACENZA. 2004. Túmulos, ideología y paisaje de la fase Alto Ramírez del Valle de Azapa. En Chungara. Revista de Antropología Chilena 36: 261-272, Arica.

SALGUERO, E. 2002. Relación entre los recursos vegetales y las prácticas ganaderas de pequeños productores en los sistemas tradicionales del Chaco Serrano del valle de Ambato (Pcia. de Catamarca. N.O.A.). Tesina de grado para la Licenciatura en Ciencias Biológicas. Facultad de Ciencias Exactas, Físicas y Naturales, Universidad Nacional de Córdoba.

SPENCE, C. 1994. Archaeological Site Manual.3rd edition. Museum of London Archaeology Service, London.

THOMAS, J. 1996. Time, Culture and Identity. An Interpretive Archaeology. Routledge, London and New York.

THOMAS, J. 2011. Archaeology and Modernity. Routledge, London and New York.

TILLEY, C. 1994. A Phenomenology of Lansdcape. Places, Paths and Monuments. Berg Publishers, Oxford and Providence. 
